\title{
OxymaPure Coupling Reagents: Beyond Solid-Phase Peptide Synthesis
}

\author{
Srinivasa Rao Manne ${ }^{a}$ \\ Beatriz G. de la Torre ${ }^{a, b}$ \\ Ayman El-Faham*c,d \\ Fernando Albericio*a,c,e,f \\ a Peptide Science Laboratory, School of Chemistry and Physics, \\ University of KwaZulu-Natal, Westville, Durban 4000, South \\ Africa \\ Albericio@ukzn.ac.za \\ - \\ ${ }^{\mathrm{b}}$ KwaZulu-Natal Research Innovation and Sequencing Platform \\ (KRISP), School of Laboratory Medicine and Medical Sciences, \\ College of Health Sciences, University of KwaZulu-Natal, \\ Durban 4041, South Africa \\ ' Department of Chemistry, College of Science, King Saud Uni- \\ versity, P.O. Box 2455, Riyadh 11451, Saudi Arabia \\ aelfaham@ksu.edu.sa \\ - $\mathrm{OK}$ ? = \\ ${ }^{d}$ Department of Chemistry, Faculty of Science, Alexandria Uni- \\ versity,, P.O. Box 426, Ibrahimia, Alexandria 21321, Egypt \\ e Institute for Advanced Chemistry of Catalonia (IQAC-CSIC), \\ Jordi Girona 18-26, 08034 Barcelona, Spain \\ $f$ CIBER-BBN, Networking Centre on Bioengineering, Biomateri- \\ als and Nanomedicine, and Department of Organic Chemistry, \\ University of Barcelona, Martí i Franqués 1-11, 08028 Barcelo- \\ na, Spain \\ - sch 4 is now Table ${ }^{1}$ and Fig 6 is now sch 20; subsequent \\ schemes/figures/tables have been renumbered as appropriate \\ Published as part of the Special Topic \\ Recent Advances in Amide Bond Formation
}

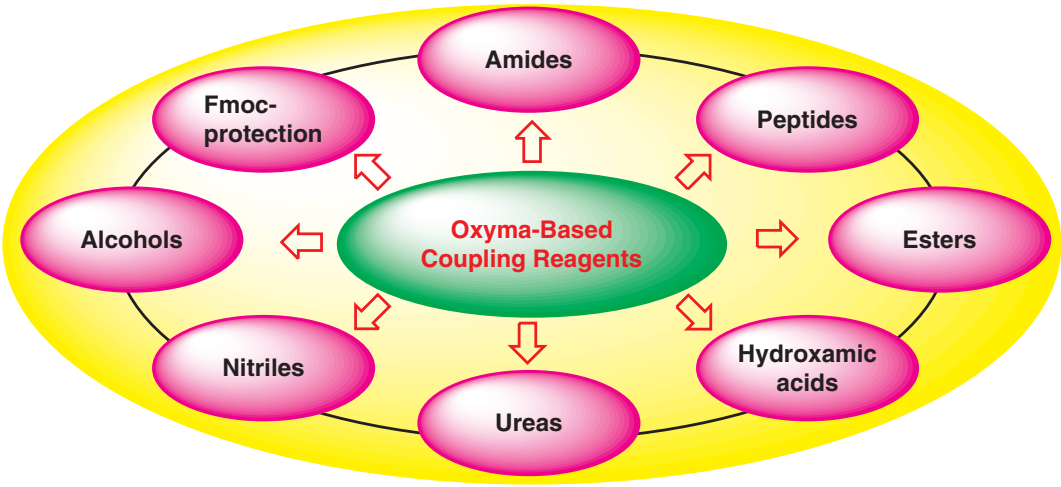

Received: 15.07.2020

Accepted after revision: 27.08.2020

Published online:

DOI: 10.1055/s-0040-1706296; Art ID: ss-2020-c0384-st

Abstract OxymaPure [ethyl 2-cyano-2-(hydroxyimino)acetate] is an exceptional reagent with which to suppress racemization and enhance coupling efficiency during amide bond formation. The tremendous popularity of OxymaPure has led to the development of several Oxymabased reagents. OxymaPure and its derived reagents are widely used in solid- and solution-phase peptide chemistry. This review summarizes the recent developments and applications of OxymaPure and Oxymabased reagents in peptide chemistry, in particular in solution-phase chemistry. Moreover, the side reaction associated with OxymaPure is also discussed.

1 Introduction

2 Oxyma-Based Coupling Reagents

2.1 Aminium/Uronium Salts of OxymaPure

2.2 Phosphonium Salts of OxymaPure

2.3 Oxyma-Based Phosphates

2.4 Sulfonate Esters of OxymaPure

2.5 Benzoate Esters of OxymaPure

2.6 Carbonates of OxymaPure Derivatives

3 OxymaPure Derivatives

4 Other Oxime-Based Additives and Coupling Reagents

Side Reactions Using OxymaPure Derivatives

Conclusion

List of Abbreviations

Key words coupling reagent, peptides, racemization, amide bonds, solid-phase synthesis

\section{Introduction}

Oximes are a class of organic compounds that have prominent structural motifs $\left(\mathrm{RR}^{\prime} \mathrm{C}=\mathrm{NOH}\right)$. They are found in numerous drug scaffolds and biologically active compounds, including natural products, pharmaceutical drugs, heterocycles and polymers. ${ }^{1-6}$ Oximes serve as key synthons for the preparation of carbonyl amines, nitriles, amides, thiohydroxamic and thiohydroxic acid derivatives, nitro compounds, and oxime esters. ${ }^{7-14}$ For example, cyclohexanone oxime is widely used in industry as a key intermediate for the synthesis of caprolactam, which is the precursor of Nylon $6 .{ }^{15}$ Oximes have also drawn considerable attention in supramolecular chemistry due to their ability to both accept and donate hydrogen bonds and thus their capacity to form dimers and catemers. ${ }^{16,17}$

Additives serve to increase coupling efficiency and control epimerization in amide bond formation, with a large number having been developed (Figure 1). In recent years, oximes and their derivatives have attracted increasing interest in the field of peptide chemistry as additives and coupling reagents, respectively. In this context, we reported the excellent performance of OxymaPure [ethyl 2-cyano-2-(hydroxyimino)acetate] (9) as a coupling enhancer and racemization suppressant in peptide synthesis. ${ }^{18}$ OxymaPure and its derivatives have been used mostly in solid-phase peptide synthesis (SPPS) mode. In 2013, we provided an exten- 
sive review of OxymaPure and its derived coupling reagents. ${ }^{19}$ Since then, this family of reagents has been subjected to a number of modifications, and a wide variety of new OxymaPure-based coupling reagents have been developed. Recently, the American Chemical Society (ACS) Green Chemistry Institute Pharmaceutical Roundtable (GCIPR) described OxymaPure and its aminium derivative COMU, together with TFFH and T3P, as the greenest coupling reagents. ${ }^{20}$
The present review aims to provide a full appreciation of Oxyma reagents in peptide chemistry, with a particular focus on their use in solution-phase synthesis since their application in solid-phase has already been covered in the aforementioned review. ${ }^{19} \mathbf{\square}$ added ref-OK? $\square$ Special attention will be paid to the applications of the most recent members of this family, as well as some side reactions that can occur under certain conditions.

\section{Biographical Sketches}
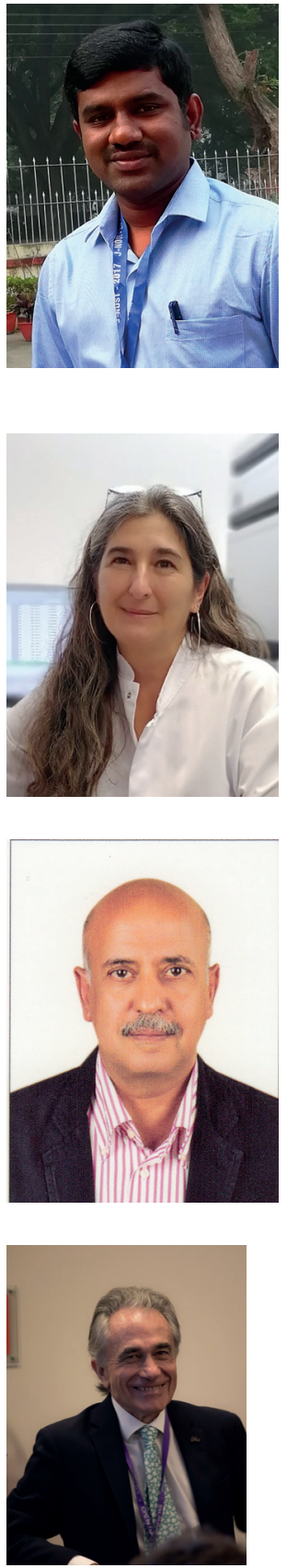

Srinivasa Rao Manne was born and raised in the small village of Mogalthur in the West Godavari district of Andhra Pradesh, India. He obtained his B.Sc. from Sri YN College, Narasapuram (India) and his M.Sc. (organic chemistry) from V.S.K. College, Bhimavaram (India). He then obtained his Ph.D. from the Indian Institute of

Beatriz G. de la Torre obtained her Ph.D. from the University of Barcelona (Spain). After a lengthy $\mathbf{a}$ change OK? - career in Spain, she is presently a Research Professor at KRISP, College of Health Sciences, University of KwaZulu-

Ayman El-Faham has been a Professor of Organic Chemistry at the College of Science, King Saud University (Saudi Arabia) since 2011. He received his B.Sc. and M.Sc. degrees from Alexandria University (Egypt) uchange OK? a and his

Fernando Albericio is a Research Professor at the University of KwaZulu-Natal (South Africa), a full Professor of Organic Chemistry at the University of Barcelona (Spain), and a Visiting Professor at King Saud
Technology Guwahati under the supervision of Professor Bhubaneswar Mandal. His work involved the applications of the novel coupling reagents BocOxyma, o-NosylOXY and nitrobenzene sulfonic acids in organic synthesis. Currently he a postdoctoral researcher in the group of Professor Fernando Albericio and Professor Beatriz G.

Natal (Durban, South Africa). During her career, she has worked extensively on glyco, nucleo-, and lipo-peptides. Her current scientific interests are focused on the discovery of new antimicrobial peptides, including antituberculosis agents

Ph.D. as a joint project between the University of Massachusetts (USA) and Alexandria University. His major scientific efforts have been concentrated on the development of new coupling reagents, first in the laboratory of Professor Carpino (םuniversi- de la Torre group at the University of KwaZulu-Natal (Durban, South Africa). His research interests are focused on peptide synthesis methodologies utilizing - nchanges OK? - peptide coupling reagents and the development of new nitrogen-protecting groups.

घchanges OK? $\mathbf{\square}$, peptidebased vaccines, and peptidebased drug-delivery systems. She is also involved in developing green solid-phase peptide synthesis (GSPPS) strategies for both research and industrial purposes.
University (Saudi Arabia). His major research interests cover practically all aspects of peptide synthetic methodology as well as the synthesis of peptides and small molecules with therapeutic activity (cancer and infec- ty, country?) $\mathbf{\square}$, and since 1993 in collaboration with Professor Albericio (University of KwaZulu-Natal, South Africa). He also has wide-ranging experience of drug discovery using relevant scaffolds. $\mathbf{\square}$ changes OK? tious diseases). He has published more than 950 scientific articles, filed more than 60 patents, and has overseen the graduation of more than 703 -uplease confirm? घ Ph.D. students. 


\section{Oxyma-Based Coupling Reagents}

\subsection{Aminium/Uronium Salts of OxymaPure}

Over the years, benzotriazole-based aminium salts such as HATU, ${ }^{21,22}$ HCTU $^{23,24}$ and HBTU ${ }^{25,26}$ have been reported to show high efficiency and good capacity to suppress racemization, and as a result, they have attracted increasing attention for amide bond formation. However, the main disadvantage of these reagents, which are based on benzotriazole scaffolds such as HOBt (1) and HOAt (3), is that they are considered as class 1 explosives, showing autocatalytic decomposition and difficult handling during transport and storage. ${ }^{27,28}$ In 2009, OxymaPure was demonstrated to outperform benzotriazole reagents in terms of yields and lower racemization and, in addition, it did not pose a risk of explosion. ${ }^{18}$ The tremendous interest in OxymaPure led to the development of the more efficient Oxyma-based uronium

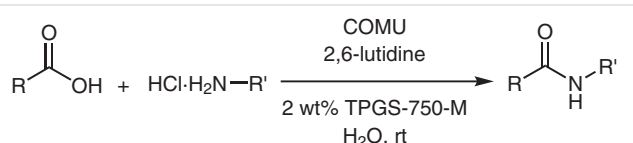

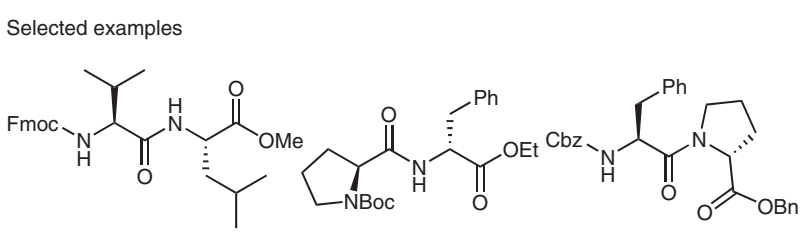<smiles>CCCCCCNC(=O)C#Cc1ccccc1</smiles>

* Wthout TPGS-750-M

$86 \%, 4 \mathrm{~h}$

Scheme 1 COMU-mediated amide bond formation in a water-based solvent mixture

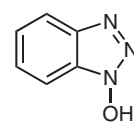<smiles>Cn1nnc2ccc(Cl)cc21</smiles><smiles>On1nnc2cccnc21</smiles><smiles>O=c1ccccn1O</smiles><smiles>O=C1CCC(=O)N1O</smiles>

HOBt (1)<smiles>[GaH2]O[GeH3]</smiles>

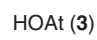

HOPO (4) HOSu (5)<smiles>O=c1c2ccccc2nnn1O</smiles><smiles>O=C1Cc2ccccc2N1O</smiles><smiles>On1c(-c2ccccc2)nc2ccccc21</smiles><smiles>CCOC(=O)/C(C#N)=N/O</smiles>

HODhbt (6)

HOBI (8)

OxymaPure (9)

Figure 1 The structures of several additives

salt COMU (10) for amide bond formation (Figure 2). ${ }^{29}$ This reagent offers unique properties over traditional benzotriazole reagents, such as higher solubility, low epimerization, ease of work-up, and high yields of products. ${ }^{30-36}$

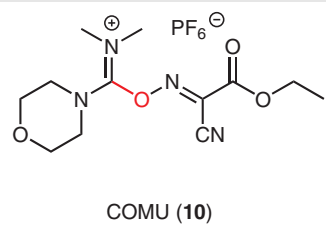

Figure 2 The structure of COMU (10)

However, COMU shows poor hydrolytic stability in DMF due to the presence of a highly reactive $\mathrm{C}-\mathrm{O}$ bond (shown in red in Figure 2). ${ }^{37}$ We recently conducted a rigorous study of the hydrolytic stability of COMU in various solvents such as $\gamma$-valerolactone (GVL), MeCN, $N$-formylmorpholine (NFM) and DMF. ${ }^{38}$ After 48 hours, COMU showed $89 \%$ and $84 \%$ hydrolytic stability in MeCN and GVL, respectively, while only $0 \%$ and $3 \%$ stability was observed in DMF and NFM, respectively.

Lipshutz and co-workers developed a convenient and versatile method for amide formation using a combination of COMU and TPGS-750-M in a water-based solvent mixture. ${ }^{39}$ Here, the surfactant TPGS-750-M played a key role in

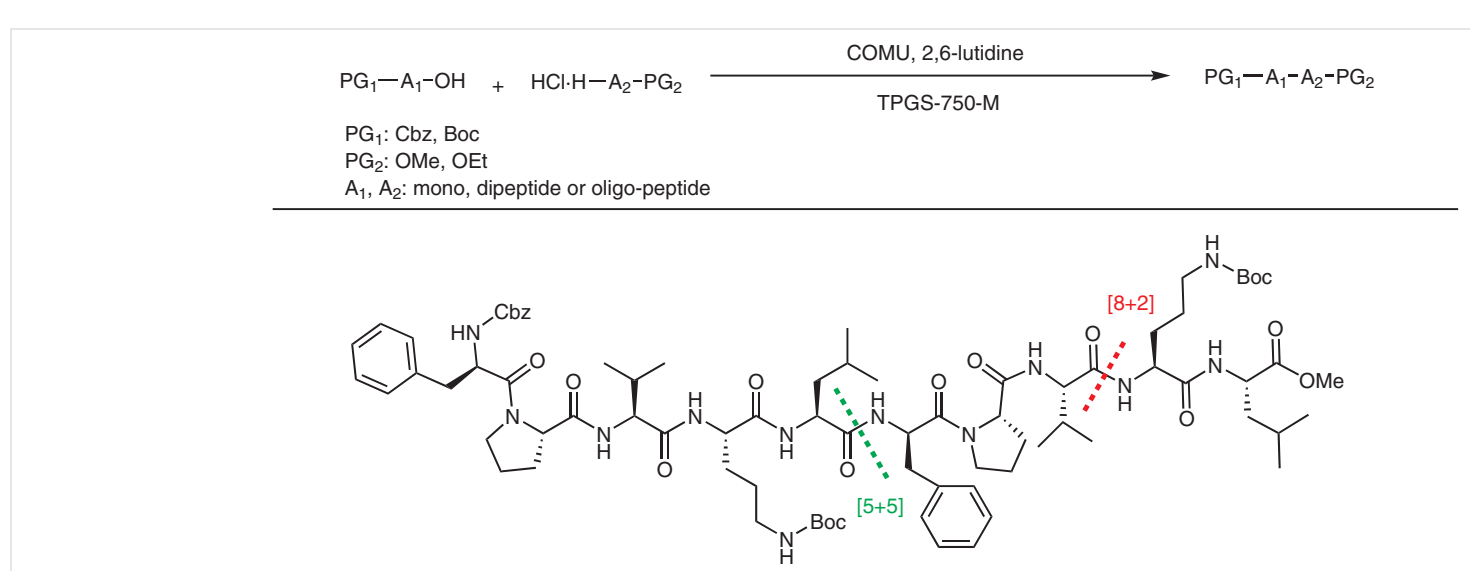

Scheme 2 Synthesis of the gramicidin S precursor via a convergent [5+5] or [8+2], two-step, one-pot approach using COMU as the coupling reagent 
the formation of the amide bond. The reaction showed compatibility with common $\mathrm{N}$-terminus protecting groups such as Fmoc, Boc, and $\mathrm{Cbz}$, along with various $C$-terminus protecting groups such as alkyl, allyl, and benzyl esters. This method afforded the coupling products in good to excellent yields. Thus, the dipeptide Fmoc-Val-Leu-OEt was formed in excellent yield (96\%), but only $53 \%$ of product formation was achieved in the absence of the surfactant. The noteworthy feature of this methodology is that it obviates the use of organic solvents, and the aqueous surfactant TPGS-750-M is recyclable, thereby making this protocol greener and environmentally friendly (Scheme 1).

Later, Lipshutz's group extended this efficient protocol using COMU as a coupling reagent to conduct solution-

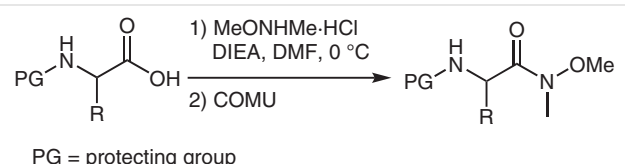

$\mathrm{R}=$ amino acid side chain

Scheme 3 Synthesis of Weinreb amides using COMU

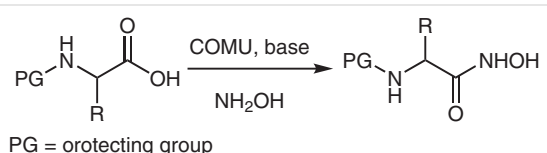
$\mathrm{R}=$ amino acid side chain

Scheme 4 Synthesis of $\mathrm{N}^{\alpha}$-protected amino/peptide hydroxamic acids phase peptide synthesis that relied on a tandem deprotection/peptide coupling under mild aqueous micellar conditions using the designer surfactant TPGS-750-M. ${ }^{40}$ This approach is broadly applicable to several types of amino acids with differing polarities and an array of varying substitution patterns on their side chains, including phenyl or alkyl moieties, protected amine or carboxylic acid, and unprotected alcohol and phenolic groups. A segment coupling process was used to extend the polypeptide length to ten amino acid residues without significant loss of efficiency. Also, no epimerization was detected (Scheme 2).

In 2011, Tyrrell et al. reported COMU as a non-hazardous reagent for the conversion of $N$-protected $\alpha$-amino acids into $\mathrm{N}$-methoxy- $\mathrm{N}$-methylamines to afford the corresponding Weinreb amides in very good to excellent yields and with minimal racemization. ${ }^{35}$ The reaction can be monitored visually by the change in color associated with the formation of the product (Scheme 3).

Twibanire and Grindley ${ }^{41}$ reported the use of COMU, TBTU, and TATU to prepare carboxylic acid esters in excellent yields from all types of alcohols at room temperature, under mild conditions in the presence of organic bases and in short reaction times. TBTU and TATU promoted esterification of secondary alcohols faster than COMU in the presence of DBU as the base. Only COMU was effective for the preparation of esters from tertiary alcohols and in the presence of the stronger base 7-methyl-1,5,7-triazabicyclo[4.4.0]dec-5-ene (MTBD) (Table 1).

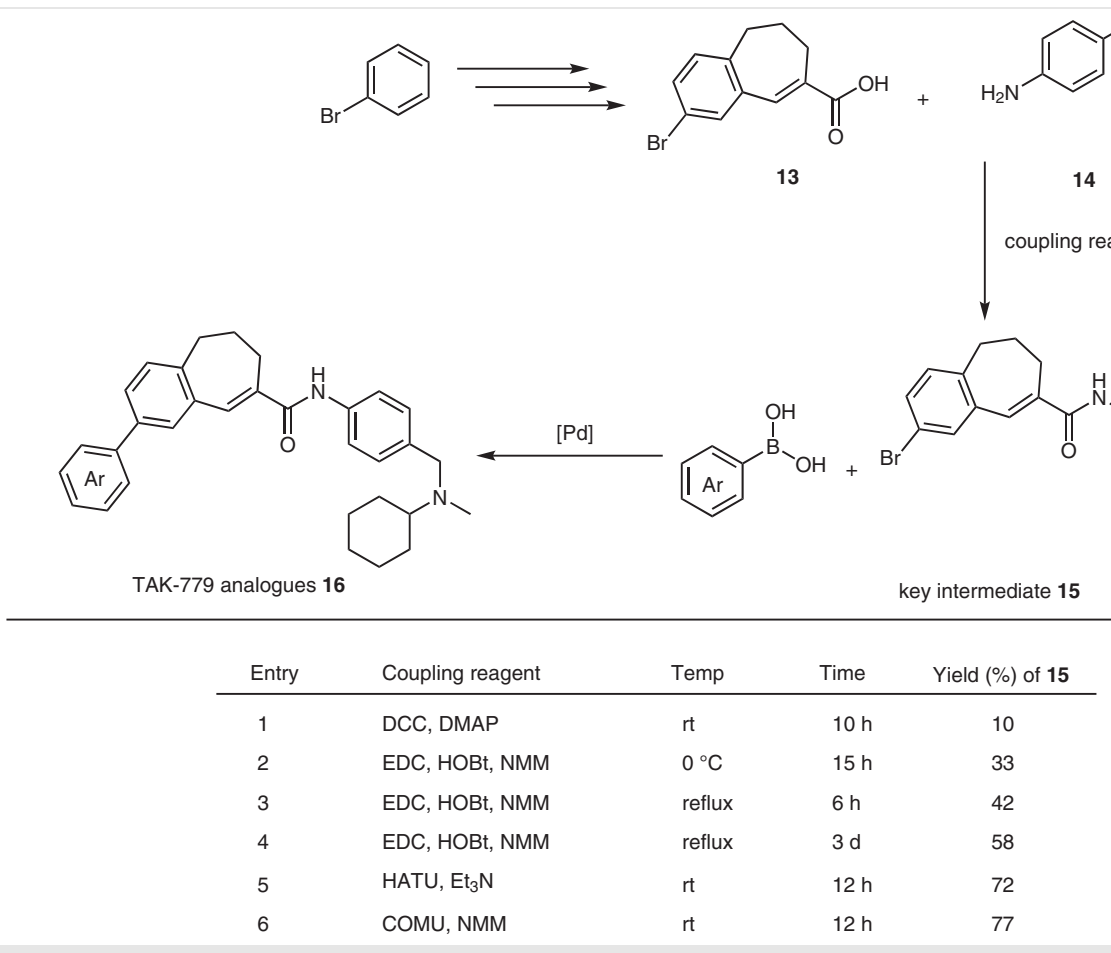

Scheme 5 Synthesis of TAK-779 analogs 16 
Table 1 Synthesis of Carboxylic Acid Esters Using COMU, TBTU, and TATU as Coupling Reagents

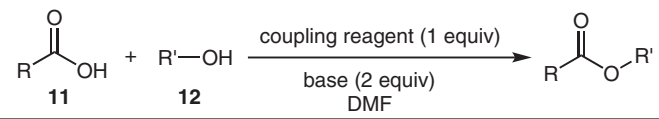
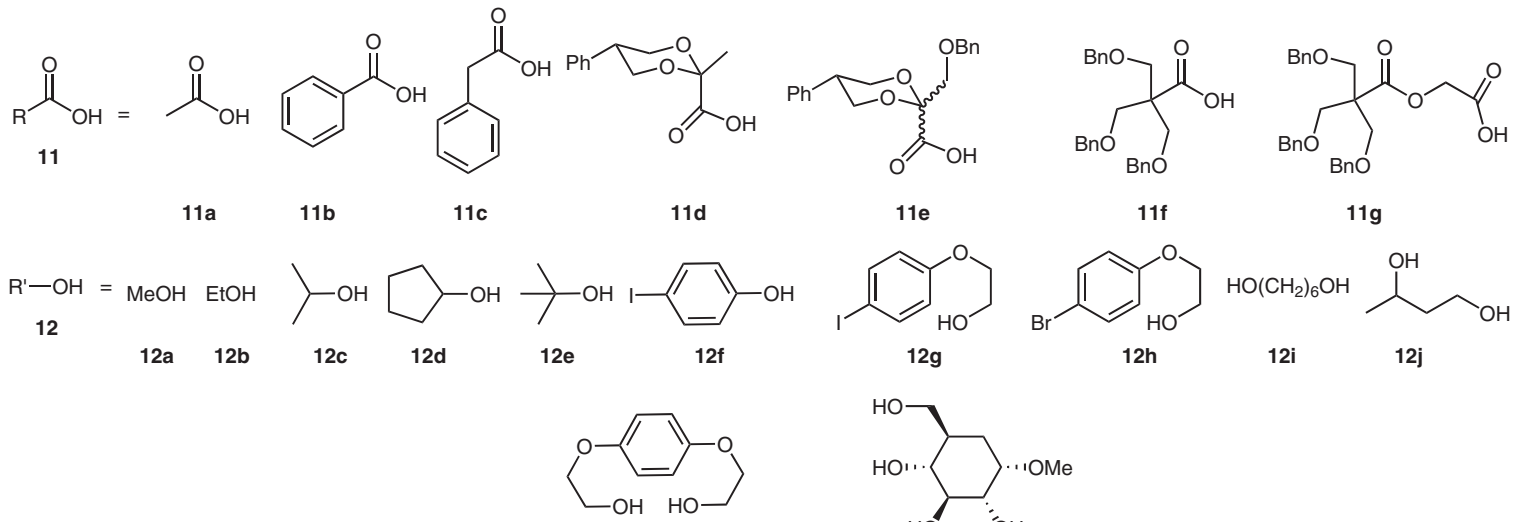

$12 k$

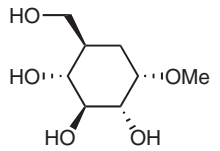

12I

\begin{tabular}{|c|c|c|c|c|c|c|}
\hline Entry & Acid & Alcohol & Coupling reagent & Base & Time (h) & Yield (\%) \\
\hline 1 & $11 b$ & $12 f$ & TBTU & DIEA & 0.25 & 86 \\
\hline 2 & $11 b$ & $12 f$ & TATU & DIEA & 0.25 & 96 \\
\hline 3 & $11 b$ & $12 f$ & COMU & DIEA & 3 & 79 \\
\hline 4 & $11 b$ & $12 b$ & COMU & DBU & 2.5 & 89 \\
\hline 5 & $11 b$ & $12 \mathrm{~g}$ & TBTU & DBU & 0.5 & 81 \\
\hline 6 & $11 b$ & $12 g$ & TATU & DIEA & 0.5 & 95 \\
\hline 7 & $11 b$ & $12 \mathrm{~g}$ & cOMU & $\mathrm{DBU}$ & 4.5 & 74 \\
\hline 8 & $11 b$ & $12 \mathrm{k}$ & COMU & DBU & 5 & 69 \\
\hline 9 & $11 b$ & $12 c$ & TBTU & DBU & 4 & 63 \\
\hline 10 & $11 b$ & $12 \mathrm{c}$ & COMU & DBU & 16 & 71 \\
\hline 11 & $11 b$ & $12 c$ & COMU & MTBD & 11 & 79 \\
\hline 12 & $11 b$ & $12 d$ & TBTU & DBU & 4 & 59 \\
\hline 13 & $11 b$ & $12 d$ & TATU & DBU & 3.5 & 89 \\
\hline 14 & $11 b$ & $12 d$ & COMU & $\mathrm{DBU}$ & 16 & 68 \\
\hline 15 & $11 b$ & $12 \mathrm{e}$ & TBTU & DBU & 36 & 0 \\
\hline 16 & $11 b$ & $12 e$ & TATU & DBU & 36 & 0 \\
\hline 17 & $11 b$ & $12 \mathrm{e}$ & COMU & DBU & 36 & 0 \\
\hline 18 & $11 b$ & $12 \mathrm{e}$ & TATU & MTBD & 36 & 0 \\
\hline 19 & $11 b$ & $12 e$ & COMU & MTBD & 16 & 79 \\
\hline 20 & $11 a$ & $12 \mathrm{~g}$ & COMU & $\mathrm{DBU}$ & 2 & 86 \\
\hline 21 & $11 c$ & $12 f$ & COMU & DBU & 3 & 81 \\
\hline 22 & $11 c$ & $12 i$ & COMU & $\mathrm{DBU}$ & 4 & 83 \\
\hline 23 & $11 c$ & $12 \mathrm{k}$ & COMU & DBU & 4 & 67 \\
\hline 24 & 11d & $12 \mathrm{~h}$ & TBTU & DBU & 1 & 72 \\
\hline 25 & 11d & $12 \mathrm{~g}$ & COMU & DBU & 12 & 73 \\
\hline 26 & $11 \mathrm{e}$ & $12 \mathrm{~g}$ & TBTU & DBU & 3 & 60 \\
\hline 27 & $11 \mathrm{e}$ & $12 \mathrm{~g}$ & COMU & $\mathrm{DBU}$ & 14 & 62 \\
\hline 28 & $11 f$ & $12 g$ & COMU & DBU & 2 & 81 \\
\hline
\end{tabular}

$\square$ there are no results for experiments with $12 a, 12 j$ and $12 l$ ? 
In 2014, Panguluri a $\mathbf{a}$ change OK? $\mathbf{\square}$ et al. ${ }^{42}$ reported a simple, one-pot protocol under mild conditions for the synthesis of $\mathrm{N}^{\alpha}$-protected amino/peptide hydroxamic acids from the corresponding carboxylic acids. In this protocol, COMU was used as an acid activator in the presence of a base such as DIEA to afford the target products in good yields and without any racemization. They also reported that this strategy was appropriate for the synthesis of simple, bifunctional and sterically hindered $\alpha$-amino/peptide hydroxamic acids (Scheme 4).

In 2014, Wunsch and co-workers demonstrated the utility of COMU for the synthesis of biologically active TAK-779 analogs, which act similarly to chemokine receptor 5 (CCR5). ${ }^{43}$ These authors developed a new methodology for the synthesis of TAK-779 analogs using a late-stage diversification strategy. The amide product 15 was a central building unit in the synthesis of these analogs and was obtained by the coupling reaction between acid 13 and aniline 14 using coupling reagents such as DCC, EDC, HATU, and COMU under a range of reaction conditions. Of these reagents, HATU and COMU were found to be effective and gave higher yields of intermediate $\mathbf{1 5}$ (Scheme 5).

In 2014, Miao et al. developed a greener synthesis of phytosphingolipidyl $\beta$-cyclodextrin derivatives. ${ }^{44}$ In this regard, the key step was the insertion of phytosphingolipidyl aphytosphingosine? $\mathbf{\square}$ using a coupling reagent. The traditional reagent DIC/HOBt gave a very poor yield (48\%), even when the amount used was increased to 30 equivalents. Alternatively, only 1.5 equivalents of HATU were needed to achieve a high yield of the desired product (90\%). However, given the high cost and explosive nature of HATU, this reagent cannot be used on an industrial scale. To overcome this problem, the authors used the less expensive and more efficient coupling reagent COMU and achieved a good yield $(80 \%)$ of the desired product. $\square$ changes OK? $\mathbf{\square}$ They reported that this methodology was safe and greener (Scheme 6).

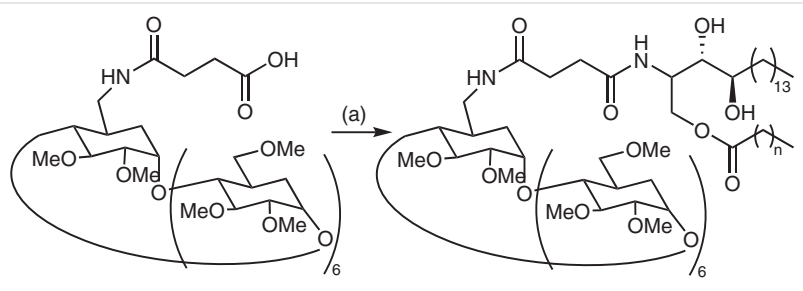
(a) phytosphingosine (10 equiv), COMU (2 equiv),
anhydrous DMF 24 h, $80 \%$

Scheme 6 Application of COMU in the synthesis of cyclodextrin derivatives
Similarly, Manabe and Ito show the applicability of COMU in the synthesis of mycothiol, which is found in Gram-positive bacteria. ${ }^{45}$ The key intermediate step in this synthesis was insertion of the Cys moiety. HATU gave a very poor yield due to the low solubility of the byproducts, which complicated column purification. However, COMU afforded an excellent yield without any difficulties during the purification process (Scheme 7).

Regarding the safety protocol required when using COMU, in 2015, Withey and Bajic ${ }^{46}$ devised a one-pot, operationally simple, safe and standard protocol to be used by undergraduate students in an organic chemistry laboratory for the preparation of $N, N^{\prime}$-diethyl-3-methylbenzamide (DEET) from $m$-toluic acid using COMU as a non-hazardous coupling reagent. The experiment benefited from short reaction times and no purification was necessary. Students were able to determine the progress of the reaction by simply monitoring the color (Scheme 8).

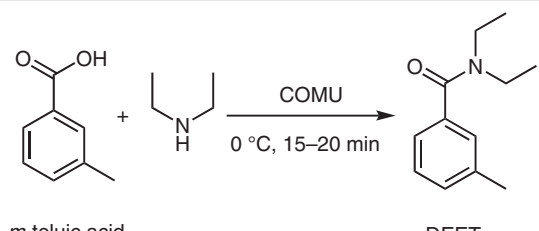

Scheme 8 An undergraduate synthesis of DEET

In 2017, Scholz and Wingen reported promising results using COMU for the synthesis of a carborane. ${ }^{47}$ Amide bond formation in carboranes is unlike that in peptides and organic compounds, and only moderate yields are obtained with other traditional methods (Scheme 9).

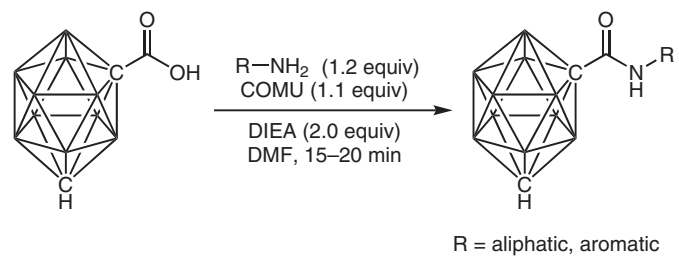

Scheme 9 Application of COMU in the synthesis of carborane derivatives

In 2017, Poock and Kalesse ${ }^{48}$ described the total synthesis of nannocystin Ax in an overall yield of $11 \%$ starting from a known aldehyde $\mathbf{a}$ changes OK? $\mathbf{n}$ building block and in 14 steps. The macrocycle was closed via a macrolactamization reaction using COMU. For this coupling, several
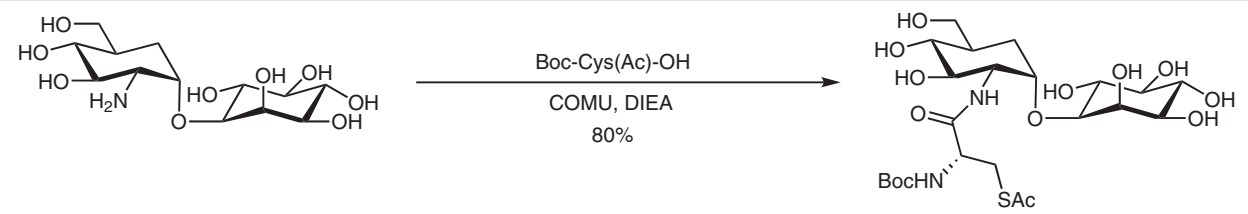

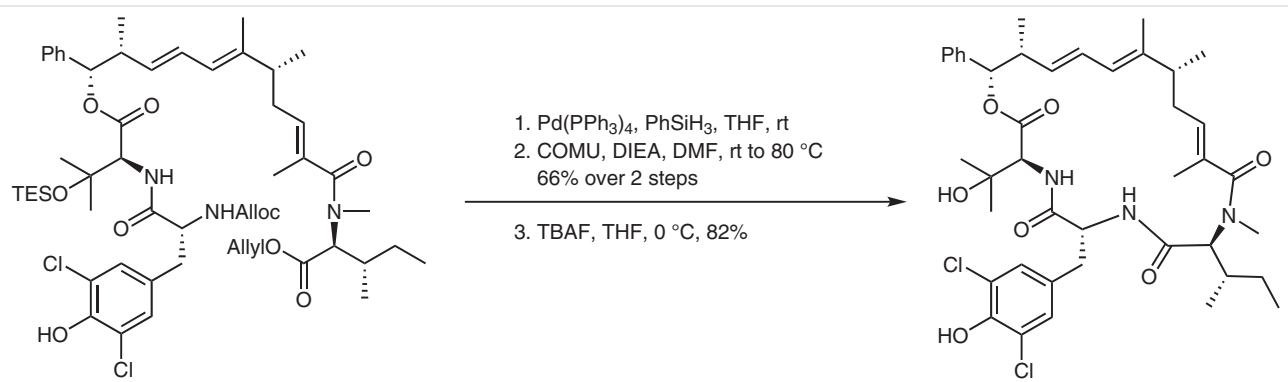

Scheme 10 A macrolactamization reaction using COMU for the synthesis of nannocystin Ax

sets of conditions were tested (e.g., PyBrop, PyClop, Oxyma, $\mathrm{EDC} \cdot \mathrm{HCl}, \mathrm{COMU}$ and DMAP), and it was found that COMU gave the best result (a 66\% yield) (Scheme 10).

Similarly, other Oxyma-based uronium salts, namely HOTU (17) and TOTU (18), have also shown better performance than benzotriazole-based reagents (Figure 3). During the formation of the dipeptide Z-Phg-Pro- $\mathrm{NH}_{2}$, very low epimerization was observed with COMU and HOTU $(0.17 \%$ and $0.12 \%$, respectively) compared to HBTU and HATU ( $8.2 \%$ and $3.1 \%$, respectively).

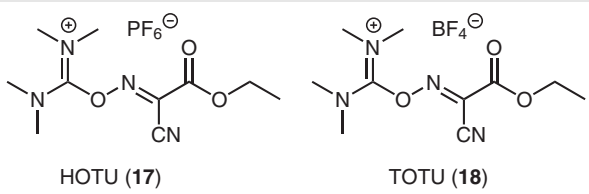

Figure 3 Structures of HOTU and TOTU

\subsection{Phosphonium Salts of OxymaPure}

The synthesis of sterically hindered or cyclic peptides typically requires longer reaction times and an excess of the coupling reagent. However, the presence of excess uronium/aminium salts as coupling reagents may cause the $\mathrm{N}$ terminus of the peptide chain to directly react with the coupling reagent and form an undesired guanidine as a side product (Scheme 11). ${ }^{49,50}$ This reaction leads to the termination of peptide chain growth. On the other hand, the phosphonium salts PyAOP, PyBOP and PyClock have shown similar coupling efficiency. ${ }^{49,51}$ The electrophilic phosphorus does not react with the amine moiety and it prevents the termination of peptide chain growth.

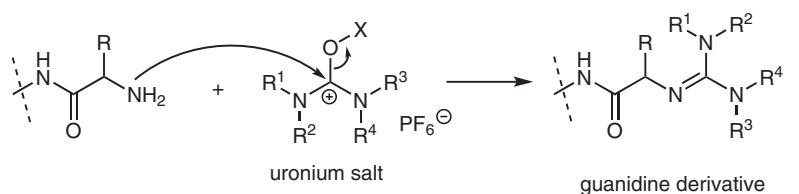

$\mathrm{R}=$ amino acid side chain

$R^{1}, R^{2}, R^{3}, R^{4}=$ alkyl

Scheme 11 Guanidine formation
In 2010, our group described the Oxyma-based phosphonium salts PyOxim (PyOxP) (19) and PyOxB (20) (Figure 4 ), as efficient alternative coupling reagents to the benzotriazole-based phosphonium salts PyAOP, РyBOP and PyClock. ${ }^{52}$ PyOxim and PyOxB showed greater capacity to suppress racemization than PyAOP, PyBOP and PyClock in a solution-phase coupling reaction. Also, PyOxim and PyOxB showed comparative results to the azabenzotriazole-derivative PyAOP and outperformed the benzotriazole derivatives PyBOP and PyClock during [2+1] segment coupling for the formation of Z-Phe-Val-Pro- $\mathrm{NH}_{2}$ (Table 2).
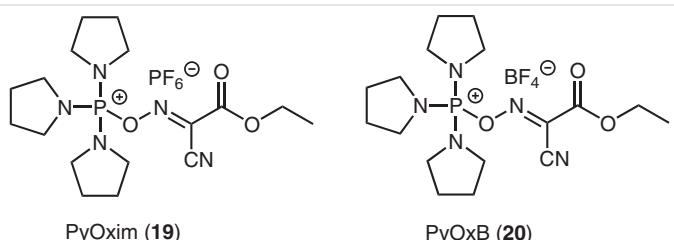

Figure 4 The structures of PyOxim and PyOxB

In addition, PyOxim showed greater performance, not only in linear peptide synthesis, but also in cyclic peptide formation. The high hydrolytic stability of PyOxim enhanced the coupling efficiency during the cyclization of the pentapeptide H-Ala-Ala-NMeAla-Ala-Ala-OH and gave superior results compared with РyBOP, PyAOP, and PyClock (Table 3).

Dettin et al., ${ }^{53}$ reported the synthesis of 15 -mer peptide nucleic acid (PNA) by solid-phase synthesis. The amino-terminal group of PNA was later condensed with bifunctional poly(ethylene oxide) derivatives (PEO, 2 and 5 KDa MW) carrying a Trt-cysteine at one end and a carboxyl group at the other end. The PNA-PEO coupling reaction proved to be sterically hindered, as demonstrated by the large excess of condensing agents necessary to achieve quantitative PNA derivatization. The use of HATU led to only $49.6 \%$ and $5.2 \%$ conversion yields, in solution- and solid-phase respectively, and to the formation of a non-PEGylated amino-modified PNA as a side product. In contrast, coupling with PyOxim was much more efficient, leading to $100 \%$ conversion to the desired conjugate, and without generating undesired side 
Table 2 Racemization During the Formation of Z-Phg-Pro- $\mathrm{NH}_{2}$ and ZPhe-Val-Pro- $\mathrm{NH}_{2}$

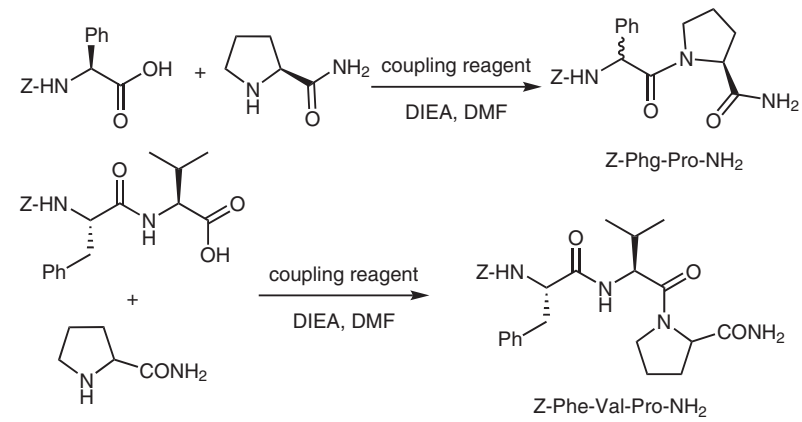

\begin{tabular}{llll}
\hline Entry & Coupling reagent & $\begin{array}{l}\text { Racemization (DL\%) } \\
\text { Z-Phg-Pro- } \mathrm{NH}_{2}\end{array}$ & $\begin{array}{l}\text { Racemization (LDL\%) } \\
\text { Z-Phe-Val-Pro-NH }\end{array}$ \\
\hline 1 & PyAOP & 2.2 & 3.0 \\
2 & PyBOP & 5.8 & 12.5 \\
3 & PyClock & 1.6 & 8.6 \\
4 & PyOxim & 0.3 & 5.7 \\
5 & PyOxB & 0.6 & 5.3 \\
\hline
\end{tabular}

products. The combination of PyOxim-based solution coupling and the optimized purification process was convenient and economical and provided the product in a mixture that could be used for surface functionalization.

Table 3 Cyclization of H-Ala-Ala-NMeAla-Ala-Ala-OH in DMF

\begin{tabular}{llcll}
\hline Entry & $\begin{array}{l}\text { Coupling } \\
\text { reagent }\end{array}$ & $\begin{array}{l}\text { Cyclic } \\
\text { peptide (\%) }\end{array}$ & $\begin{array}{l}\text { Linear peptide } \\
\mathbf{0} \text { OK? }\end{array}\left(\begin{array}{l}\text { Linear dimer } \\
(\%)\end{array}\right.$ \\
\hline 1 & PyAOP & 54 & 10 & 36 \\
2 & PyBOP & 43 & 28 & 29 \\
3 & PyClock & 61 & 15 & 24 \\
4 & PyOxim & 70 & 10 & 20 \\
5 & PyOxB & 47 & 15 & 38 \\
\hline
\end{tabular}

\subsection{Oxyma-Based Phosphates}

In 2013 -2014 in ref 54? घ, our group reported novel Oxyma-based organophosphorus reagents for coupling reactions. ${ }^{54}$ The nucleophilic additives HOBt, HOAt, Oxyma-

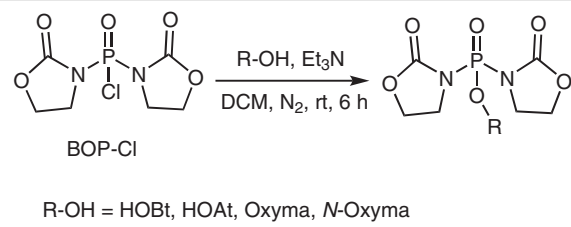

Scheme 12 Synthesis of an organophosphorus reagent
Pure and $\mathrm{N}$-Oxyma (carboxamide instead of ethyl ester) reacted with $\mathrm{BOP}-\mathrm{Cl}$ in the presence of $\mathrm{Et}_{3} \mathrm{~N}$, forming the corresponding phosphinic reagent (Scheme 12). Among these reagents, BOP-Oxy showed higher solubility in DMF and $\mathrm{MeCN}$. Also, BOP-Oxy outperformed the other reagents tested in terms of yield and epimerization control in the stepwise solution-phase synthesis of Z-Phg-Pro- $\mathrm{NH}_{2}$ and the [2+1] segment coupling for the synthesis of Z-Phe-ValPro- $\mathrm{NH}_{2}$ and Z-Gly-Phe-Pro- $\mathrm{NH}_{2}$. The major advantage of these organophosphorus coupling reagents is that they do not contain any counter anion, such as $\mathrm{PF}_{6}$ or $\mathrm{BH}_{4}$, that can hamper the final purification of a peptide.

Recently, Mitachi et al. developed the Oxyma-derived phosphates diethylphosphoryl-Oxyma (DPOx) (21) and diethylphosphoryl-glyceroacetonide-Oxyma (DPGOx) (22) for amide bond formation (Figure 5). ${ }^{55}$ They demonstrated that DPGOx shows relative stability in aprotic solvents such as anhydrous DMF and that it is an effective coupling reagent for $N$-acyl-protected $\alpha$-amino acids and oligopeptide segment coupling. The hydrolytic stability of diethylphosphoryl-Oxyma derivatives was monitored by ${ }^{1} \mathrm{H}$ NMR studies. DPOx and DPGOx were hydrolyzed in $\mathrm{H}_{2} \mathrm{O}\left(t_{1 / 2}<3 \mathrm{~h}\right)$ and slowly reacted in DMSO. Also, they were stable in DMF and $\mathrm{MeCN}$ over 5 days. Furthermore, diethylphosphorylOxyma derivatives showed better stability in anhydrous DMF in the presence of $\mathrm{NaHCO}_{3}$ and did not display any measurable decomposition even after 24 hours. The authors found that DPOx and DPGOx were stable in DMF at room temperature and could be stored for more than 30 days under these conditions.
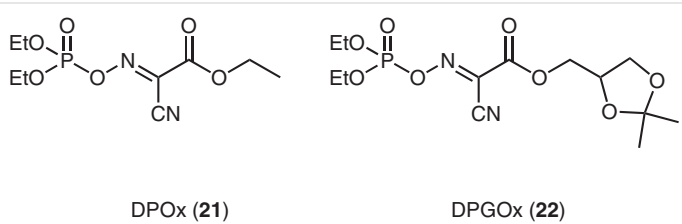

Figure 5 The structures of DPOx and DPGOx

DPGOx allowed for the racemization-free synthesis of $\mathrm{N}$-acyl and $\mathrm{N}$-formyl dipeptides, pentapeptides, and hexapeptides, with excellent yields. $\square r e f .55$ ? $\square$ This was the first report of this diethylphosphoryl-Oxyma derivative being used to synthesize $N$-formyl peptides, a process in which it is very difficult to perform the coupling reaction. DPGOx proved efficient for the synthesis of 18-mers of linear oligopeptides, cyclic peptides and complexes of glycopeptides. Also, DPGOx gave an impressive performance in $[6+3]$ and $[3+9]$ segment coupling reactions, the antibacterial peptide fragment being obtained with $92 \%$ purity through [6+3] segment coupling reactions. In addition, it was effective for macrolactamizations to form lactams of medium ring size. The reaction rate of the DPGOx-promoted macrolactamizations was much faster than that achieved when using diphenyl phosphoryl azide (DPPA) (Scheme 13). 


\subsection{Sulfonate Esters of OxymaPure}

In 2010, Khattab introduced a new family of Oxyma sulfonate esters, namely TsOXY and NpsOXY, to facilitate coupling reactions (Scheme 14). ${ }^{56}$ These reagents show high efficiency in preactivations within a short period and high stability to the moisture in air. The racemization associated with the use of these reagents was examined in the synthesis of the dipeptide Z-Phe-Val-OMe and compared with the performance of benzotriazole derivatives. The Oxyma sulfonate esters outperformed these derivatives in terms of preactivation times, yields and racemization suppression (Table 4).

(a)

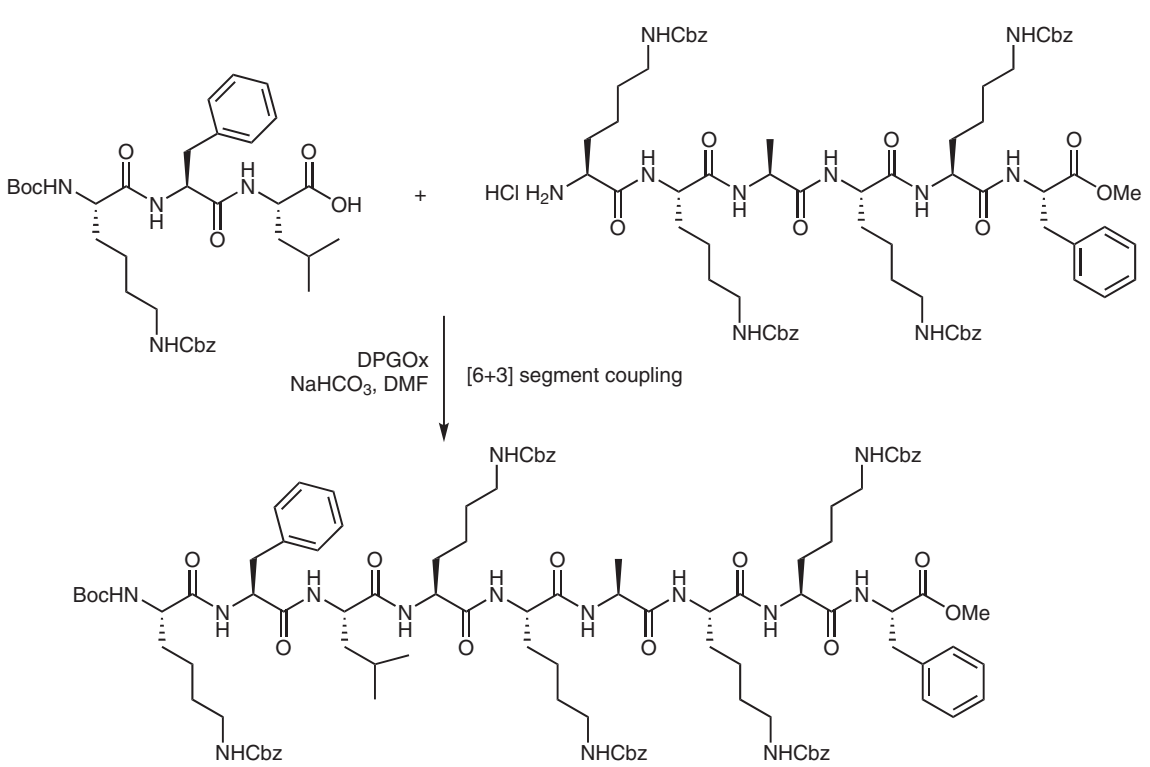

(b)

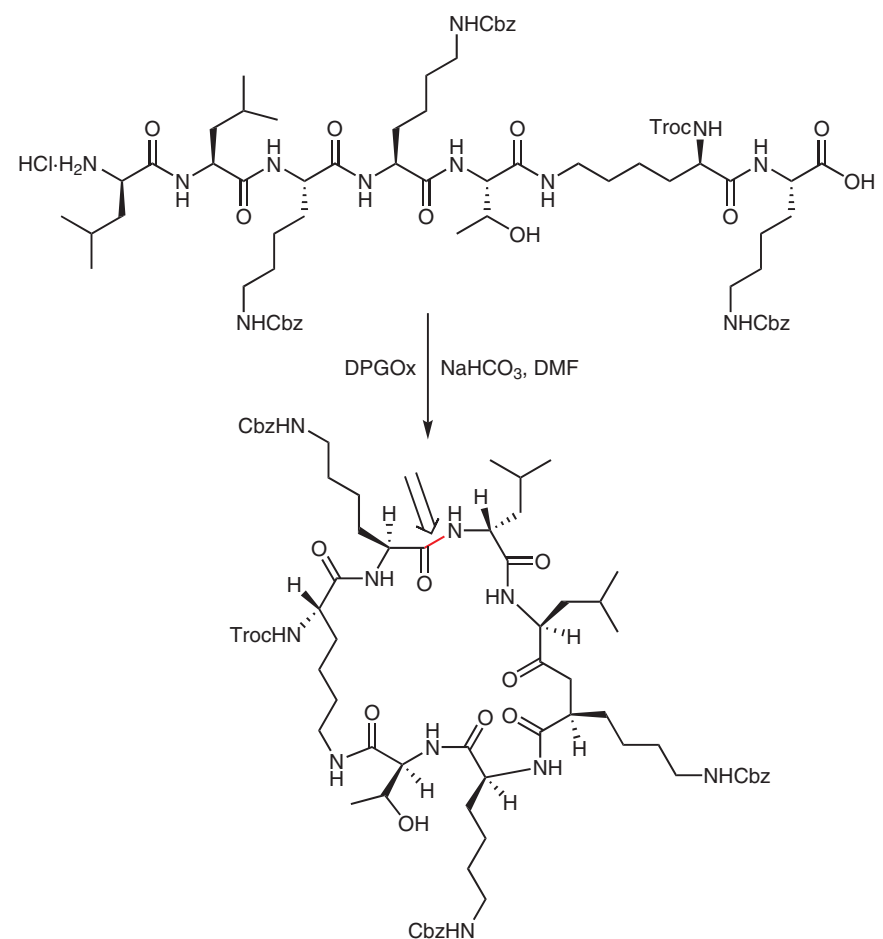

Scheme 13 DPGOx-mediated (a) [6+3] segment coupling, and (b) macrolactamization 

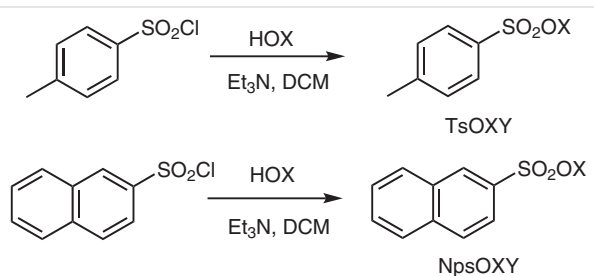

HOX $=$ HOBt, 7-HOAt, HOPO, OxymaPure

Scheme 14 Synthesis of sulfonate-ester-type coupling reagents - alabeled products-OK? -

Table 4 Yield and Racemization During the Solution-Phase Synthesis of Z-Phe-Val-OMe

\begin{tabular}{llccc}
\hline Entry & $\begin{array}{l}\text { Coupling } \\
\text { reagent }\end{array}$ & $\begin{array}{l}\text { Preactivation } \\
\text { time }(\mathrm{min})\end{array}$ & $\begin{array}{l}\text { Yield } \\
(\%)\end{array}$ & \multicolumn{1}{l}{$\begin{array}{l}\mathrm{DL} \\
(\%)\end{array}$} \\
\hline 1 & NpsOAt & 120 & 54.5 & 6.7 \\
2 & NpsOBt & 120 & 69.4 & 12.9 \\
3 & NpsOPO & 120 & 69.8 & 7.2 \\
4 & NpsOxyma & 3 & 92.5 & 4.8 \\
5 & TsOAt & 120 & 45.8 & 11.0 \\
6 & TsOBt & 120 & 52.2 & 1.4 \\
7 & TsOPy & 120 & 63.7 & 4.1 \\
8 & TsOxyma & 3 & 91.5 & 2.0 \\
\hline
\end{tabular}

In 2013, Mandal and co-workers also prepared various Oxyma sulfonate esters and used them as precursors in the synthesis of sulfonamides. ${ }^{57}$ The main advantages of this protocol were that the synthesis was $\mathrm{HCl}$-free and it worked well with even less nucleophilic anilines (Scheme 15).

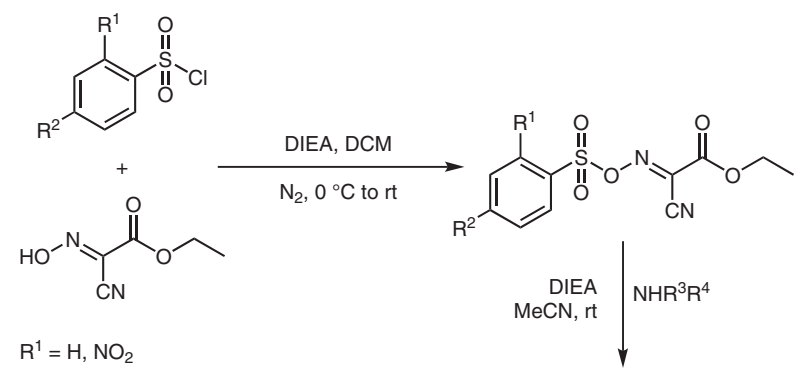

$\mathrm{R}^{2}=\mathrm{H}, \mathrm{Me}, \mathrm{NO}_{2}$

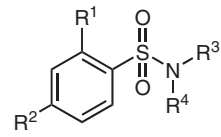

Scheme 15 Synthesis of sulfonamides

Furthermore, Mandal reported Oxyma sulfonate esters as efficient promotors for the conversion of aldoximes into nitriles under mild conditions. ${ }^{58}$ The reaction mechanism proposed was through nucleophilic aldoxime attack on ei- ther the electrophilic center of sulfur (path A) or the electrophilic center of the carbonyl carbon (path B) of the Oxyma sulfonate esters. NMR and X-ray anchange OK? $\mathbf{\square}$ crystal studies of the intermediates revealed, unexpectedly, that the reaction mechanism was more favorable through the involvement of the OxymaPure-cleaved product of path B (Scheme 16).

Later, in 2014, the same group developed a novel and reliable Oxyma-based coupling reagent, ethyl 2-cyano-2-(2nitrobenzenesulfonyloxyimino)acetate (o-NosylOXY), to replace benzotriazole-based reagents. ${ }^{59} 0$-NosylOXY readily activates carboxylic acids to afford amides, peptides, esters, thioesters, hydroxamates, alcohols and heterocyclic compounds. ${ }^{60,61}$ As a salient $\mathbf{\square}$ changes OK? $\mathbf{\square}$ feature of the reagent, after completion of the reaction it produces only the solid byproducts OxymaPure and 2-nitrobenzene sulfonic acid, which can be recovered easily and reused to prepare the same coupling reagent (Scheme 17).

The scope of the application of $o$-NosylOXY was extended to peptide synthesis. The solution-phase approach to the hydrophobic fragment of the amyloid $\beta$-peptide Boc-ValVal-Ile-Ala-OMe ${ }^{62}$ was achieved in $78 \%$ yield using Bocbased peptide synthesis. Furthermore, this approach was extended to SPPS by preparing long-chain peptides. The capacity of $o$-NosylOXY to suppress racemization was studied in the synthesis of the tripeptide Z-Gly-Phe-Val-OMe. No racemization was observed during the coupling reaction between Z-Gly-Phe-OH and H-Val-OMe. However, other reported reagents afforded good yields but racemization was noted (Table 5).

Table 5 Yield and Racemization During the Formation of Z-Gly-PheVal-OMe

\begin{tabular}{llll}
\hline Entry & Coupling reagent & Yield (\%) & Racemization (\%) \\
\hline 1 & HBTU & 89 & 5.9 \\
2 & HATU & 90 & 1.6 \\
3 & HDMB & 90 & 2.9 \\
4 & HDMA & 90 & 0.7 \\
5 & o-NosylOXY & 91 & $-^{\text {a }}$ \\
\hline a No racemization detected. & &
\end{tabular}

Similarly, another Oxyma-based reagent, namely ethyl 2-cyano-2-(4-nitrophenylsulfonyloxyimino)acetate (4NBsOXY), was reported by the same group. ${ }^{63} \mathrm{~A}$ mild and efficient method for the synthesis of hydroxamic acids directly from carboxylic acids using 4-NBsOXY was described. Also, 4-NBsOXY activated the hydroxamic acids to generate isocyanates via the Lossen rearrangement. Furthermore, these isocyanates reacted with nucleophilic amines and formed the corresponding ureas. This protocol successfully achieved a variety of aliphatic, aromatic and common $\mathrm{N}$ - 


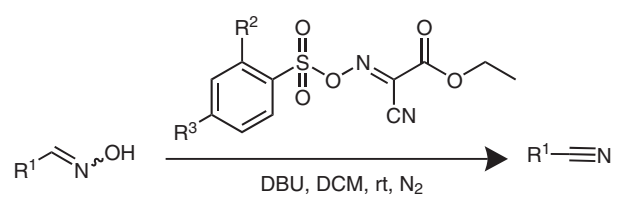

$\mathrm{R}^{1}=$ alkyl, aryl

$\mathrm{R}^{2}=\mathrm{H}, \mathrm{NO}_{2}$

$\mathrm{R}^{3}=\mathrm{H}, \mathrm{Me}, \mathrm{NO}_{2}$

Plausible reaction mechanisms

Path A:

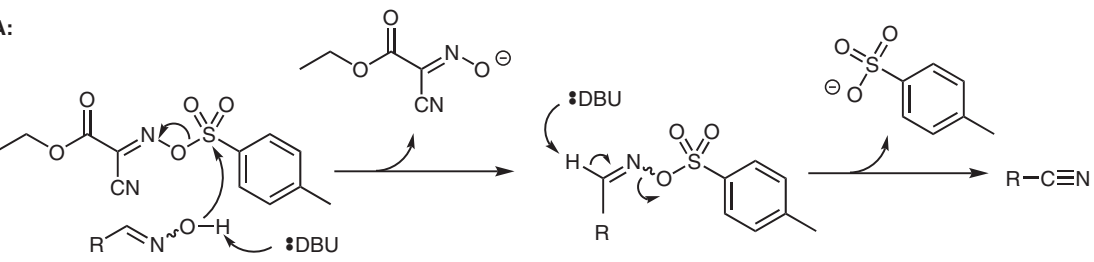

Path B:

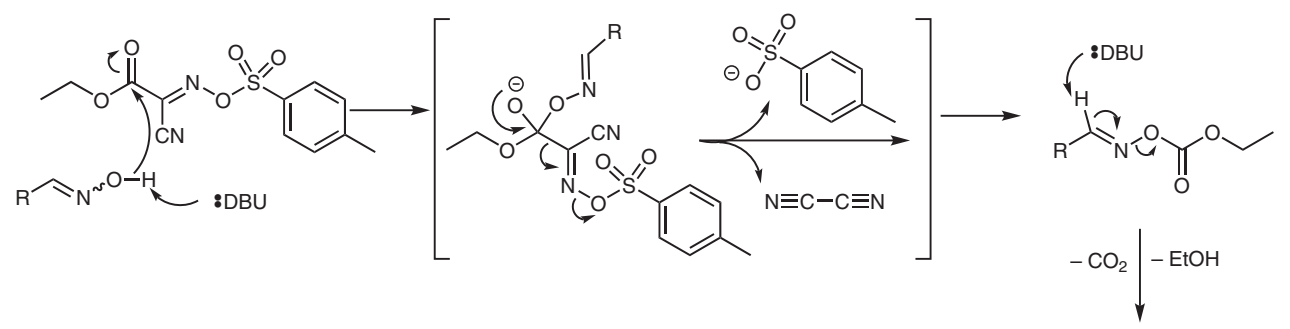

Scheme 16 Synthesis of nitriles from aldoximes using sulfonate esters

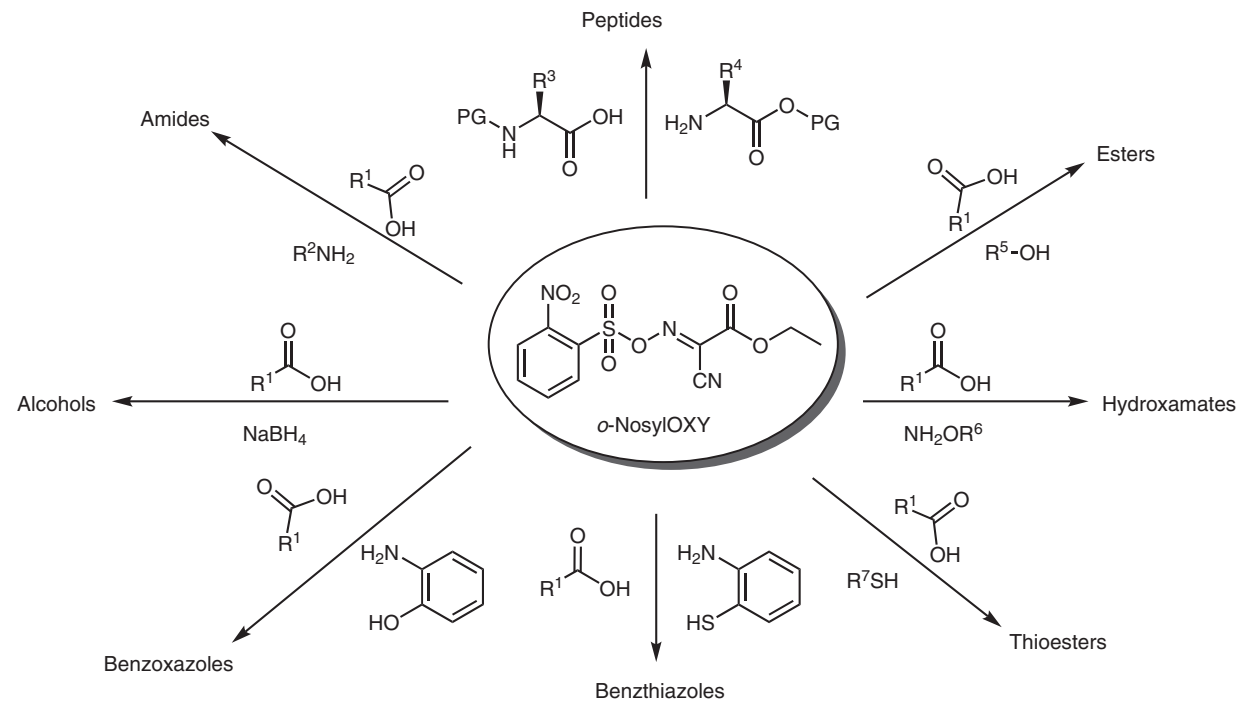

Scheme 17 o-NosylOXY-based coupling reactions $\mathbf{m}$ NBs now Nosyl-OK? 
protected amino acids containing hydroxamic acids and peptidyl ureas amade plural-OK? $\square$ without any epimerization (Scheme 18).

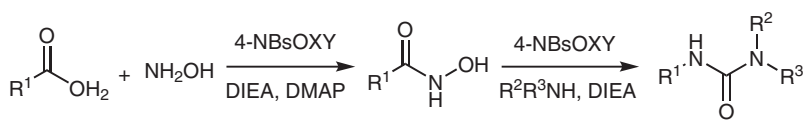

Scheme 18 Synthesis of hydroxamic acids and ureas using 4-NBsOXY

\subsection{Benzoate Esters of OxymaPure}

In 2018, Mandal and co-workers reported (E)-ethyl-2cyano-2-\{[(2,4,6-trichlorobenzoyl)oxy]imino\}acetate (TC$\mathrm{BOXY}$ ) as an Oxyma-based modified Yamaguchi reagent for acylation. ${ }^{64}$ In this work, the authors reported the first racemization-free synthesis of amides and peptides using a modified Yamaguchi reagent. The reagent TCBOXY alone gave only $30 \%$ of the desired product, with the undesired product, namely the amide of 2,4,6-trichlorobenzoic acid, predominating $(60 \%)$. Surprisingly, TCBOXY produced a high yield of the desired product (91\%) in the presence of a catalytic amount of DMAP (Scheme 19). The coupling efficiency of TCBOXY was tested in both solution-phase and solid-phase peptide synthesis. It showed impressive performance during the stepwise coupling solution-phase synthesis of a tetrapeptide, Boc-Val-Val-Ile-Ala-OMe (overall $75 \%$ crude yield). Also, the authors used TCBOXY to achieve the racemization-free synthesis of esters and thioesters.

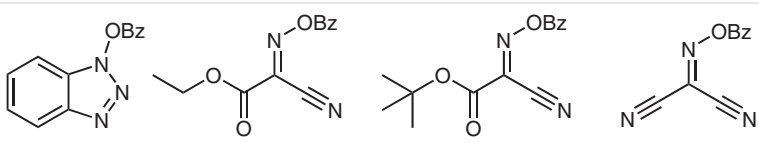

23<smiles>CCCON=C(C(=O)OCC)C(=O)OCC</smiles>

24<smiles>CC(C)(C)OC=NC1=C(OC(C)(C)C)C(=O)OC(C)(C)O1</smiles>

28
25<smiles>CN1C(=O)NC(=O)C(=NOC(C)(C)C)C1=O</smiles>

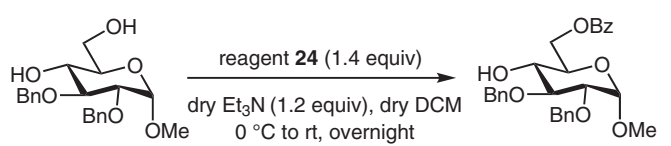

Scheme 20 Structures of benzoylated derivatives 24-29 and the synthesis of a benzoylated carbohydrate $\mathbf{\square}$ changes OK? $\mathbf{\square}$

In 2016, Burugupalli et al. reported benzoyl-Oxyma, an efficient reagent for the benzoylation of alcohols, as an alternative to HOBt-derived benzoyloxybenzotriazole (BBTZ) (23). ${ }^{65}$ The authors synthesized a series of benzoylated oximes 24-29 by changing the electron-withdrawing substituent adjacent to the oxime group (Scheme 20). The oximederived reagents 24, 25 and $\mathbf{2 6}$ afforded excellent yields during the benzoylation of primary alcohols; these yields were very similar to those obtained with the reagent BBTZ. The other oxime-derived reagents 27, 28 and $\mathbf{2 9}$ did not give satisfactory results. Furthermore, these authors extended the application of benzoyl-Oxyma to the selective acylation of carbohydrate alcohols (Scheme 20).

\subsection{Carbonates of OxymaPure Derivatives}

In 2013, Mandal and co-workers prepared a novel Oxyma-based reagent, 2-(tert-butoxycarbonyloxyimino)-2-cyanoacetate (Boc-Oxyma) (30), which was successfully tested

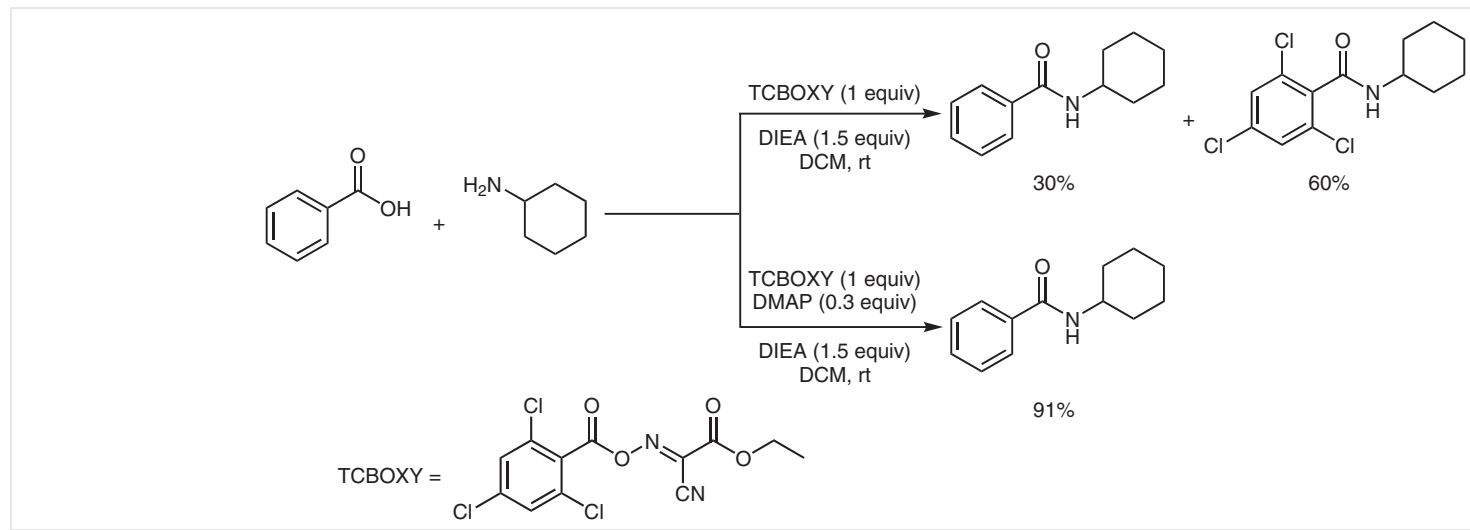

Scheme 19 TCBOXY-mediated amide formation 

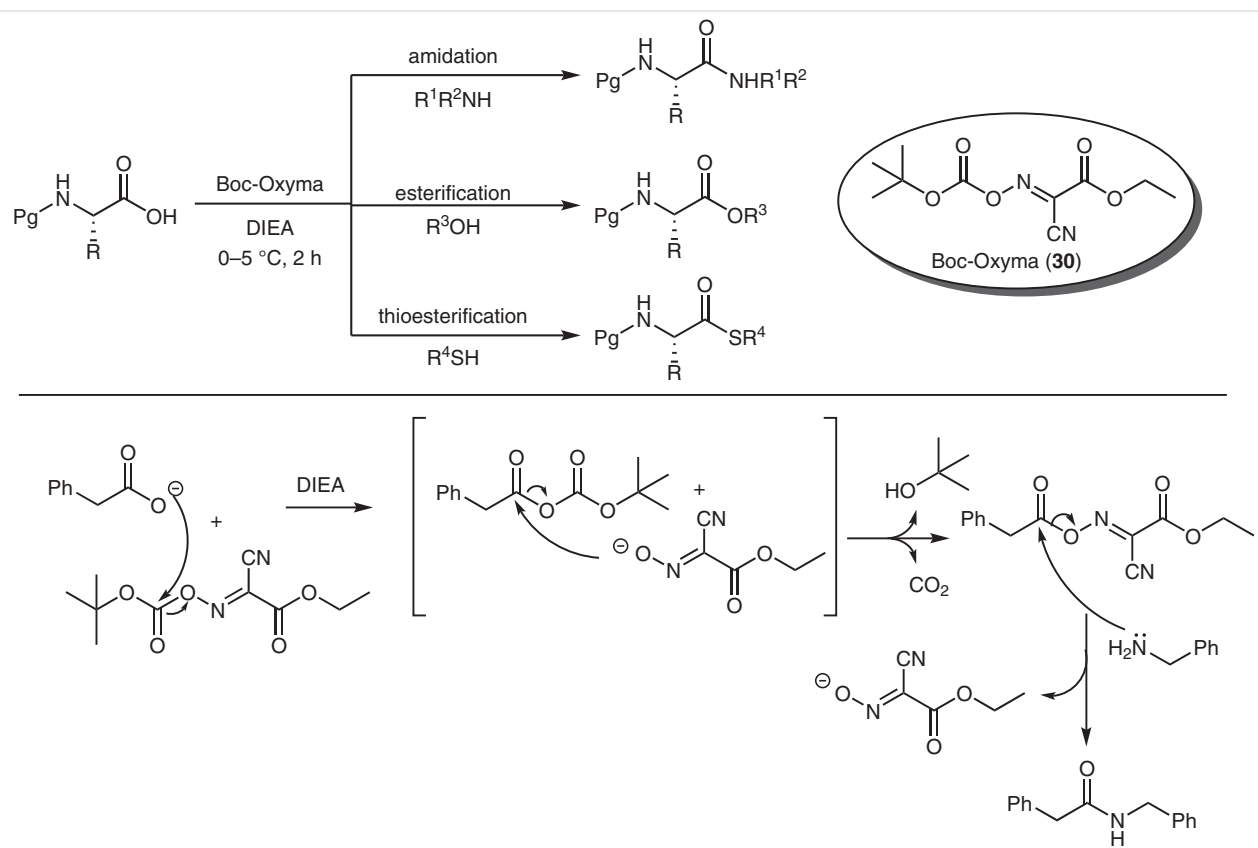

Scheme 21 A plausible reaction mechanism for Boc-Oxyma-mediated amide bond formation $\mathbf{a}(-)$ now circled negative charge (twice)-OK?

in coupling reactions. It proved to be an efficient coupling reagent for the synthesis of amides, peptides, esters and thioesters, without loss of chiral integrity. ${ }^{66}$ On the bases of NMR, IR and X-ray $\mathbf{m}$ change OK? $\mathbf{\square}$ crystal studies, a plausible reaction mechanism is depicted in Scheme 21. The carboxylate anion reacts with Boc-Oxyma to form a stable Oxyma ester via an anhydride intermediate. Subsequently, the nucleophilic amine reacts with the Oxyma ester and forms the desired amide product. Boc-Oxyma has several notable features: it is easy to prepare, it produces only solid waste OxymaPure as a byproduct, and it can be recovered easily and reused. Also, the protocol does not re- quire any strong bases during the esterification with secondary and tert-butyl alcohols, with the mild base DIEA sufficing (Scheme 21).

In 2015, further work by Mandal's group used Boc-Oxyma for the synthesis of hydroxamic acids. ${ }^{67}$ This method has been successfully applied for both aromatic and aliphatic carboxylic acids and common $\mathrm{N}$-protected amino acids. Also, these authors extended this approach to the synthesis of long-chain peptide hydroxamic acids using the Fmoc-based SPPS protocol. Furthermore, they demonstrated the applicability of this protocol in medicinal chemistry by synthesizing the anticancer agent suberoylanilide hy-

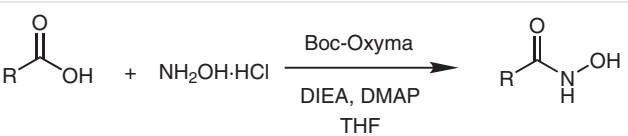

$$
\begin{aligned}
& \mathrm{R}=\text { aliphatic, aromatic acids, } \\
& \mathrm{N} \text {-protected smino acids }
\end{aligned}
$$

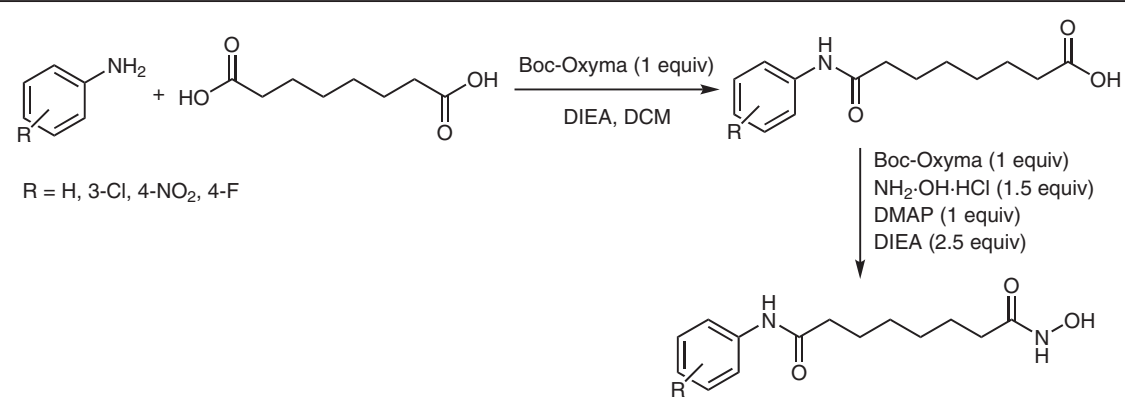

Scheme 22 Synthesis of hydroxamic acids using Boc-Oxyma a compd no 13 deleted-OK? $\mathbf{\square}$ 
droxamic acid $33,68,69$ and its derivatives. ${ }^{70}$ It is notable that both steps were achieved with the same coupling reagent (Scheme 22).

Later, in 2017, the same group reported Boc-Oxyma as an efficient promoter of the conversion of hydroxamic acids into urea derivatives via the Lossen rearrangement. ${ }^{71}$ Initially, the hydroxamic acid reacts with Boc-Oxyma in the presence of DIEA at room temperature to give the corresponding isocyanate via the Lossen rearrangement. Further, the isocyanate is subsequently trapped with nucleophilic amines leading to the desired urea derivatives. A wide variety of urea derivatives were synthesized, including simple, dipeptidyl and tripeptidyl ureas, in good to excellent yields. Interestingly, the protocol showed excellent stereoselectivity, and all the final products were obtained without any epimerization. However, this method failed to produce carbamates and thiocarbamates under identical reaction conditions. Mandal also optimized the reaction conditions and found that the best results were obtained in the presence of a catalytic amount of DMAP under reflux conditions (Scheme 23).

$$
\underset{\substack{\text { DIEA, DCM, } 60{ }^{\circ} \mathrm{C} \\ \text { up to } 80 \%}}{\text { Boc-Oxyma }}
$$

$\mathrm{R}^{1}, \mathrm{R}^{2}, \mathrm{R}^{3}=$ aliphatic, aromatic, $C$ - or $\mathrm{N}$-protected amino acids

Scheme 23 Synthesis of ureas, carbamates and thiocarbamates using Boc-Oxyma

In 2010, our group synthesized Fmoc/Alloc-oxime reagents and examined their efficiency for the introduction of the Fmoc/Alloc group. ${ }^{72}$ Most commonly, Fmoc/Alloc- $\mathrm{Cl},{ }^{73,74}$ Fmoc/Alloc-OSu, ${ }^{75,76}$ and Fmoc/Alloc- $\mathrm{N}_{3}{ }^{77}$ reagents were used to synthesize Fmoc/Alloc-protected amino acids. However, these reagents have several drawbacks, for example, highly reactive chlorides may lead to the formation of dipeptide and tripeptide impurities along with the desired $\mathrm{N}$-protected amino acids. ${ }^{78}$ The OSu derivatives can lead to the formation of $\beta$-alanine or even $\beta$-alanine-containing dipeptides through a Lossen rearrangement, ${ }^{79}$ whilst the azide derivatives can be dangerous. Interestingly, the Fmocoximes showed less than $0.6 \%$ of Fmoc-Gly-Gly-OH dipeptide formation during the preparation of Fmoc-Gly-OH. Of these reagents, Fmoc-cyanopyridyloxime afforded the best results in terms of yield, purity and low dipeptide formation. Similarly, Alloc-cyanopyridyloxime afforded Alloc-Gly$\mathrm{OH}$ in good yield, high purity and with negligible dipeptide formation. The disadvantage of this protocol is that it involves the use of an expensive cyanopyridyloxime, which is difficult to remove from the reaction mixture (Table 6).
Later, in 2017, our group developed another oximebased derivative, namely Fmoc-Amox (Table 6, entry 6), to tackle the drawbacks associated with Fmoc-cyanopyridyloxime.$^{80}$ Fmoc-Amox provides Fmoc-Gly-OH with high purity and without the formation of any dipeptide impurity. Fmoc-Amox is cheaper than Fmoc-cyanopyridyloxime. In addition, after completion of the reaction, it produces only Amox as a solid byproduct, and this can be removed easily by washing with water. These features make this protocol of high interest from an economic point of view.

Table 6 Introduction of Fmoc Using Fmoc-oximes

Entry

a Fmoc missing from the structures in table 6? $\mathbf{\square}$

\section{OxymaPure Derivatives}

Over the years, several modifications have been made to the structure of OxymaPure. The acidity of this compound $\left(\mathrm{p} K_{\mathrm{a}} \text { is } 4.60\right)^{81}$ plays a vital role in the reactivity of the additives and the stability of the active esters. However, despite the very low acidity highly acid-sensitive moieties were affected. For example, 2-chlorotritylchloride (CTC) resin, is 
highly acid-sensitive and can release prematurely the growing peptide chain. ${ }^{82,83}$ In 2013, our group synthesized the potassium salt, K-Oxyma, of OxymaPure in order to suppress the acidity (Scheme 24). ${ }^{84}$ The thermal stability, coupling efficiency and epimerization control of K-Oxyma resemble those of OxymaPure. In addition, K-Oxyma outperformed OxymaPure in solid-phase elongation with acidsensitive solid supports. The stepwise solid-phase coupling of myelin basic protein (MBP) 104-118 (H-Gly-Lys-Gly-ArgGly-Leu-Ser-Leu-Ser-Arg-Phe-Ser-Trp-Gly-Ala-OH) ${ }^{85}$ on acid-sensitive CTC resin was tested. K-Oxyma not only afforded higher yields than OxymaPure (90\% vs 63\%) but also gave a higher purity of the desired peptide ( $91 \%$ vs $88 \%$ ).

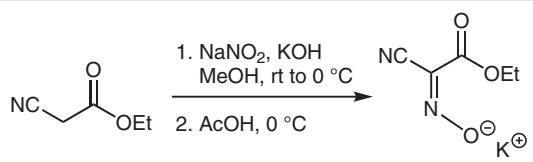

Scheme 24 Synthesis of K-Oxyma

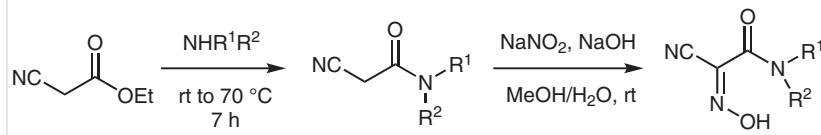

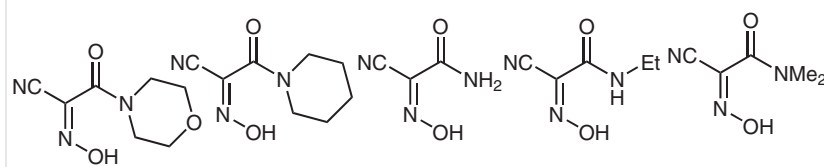

MorOx (31) PipOx (32) AmOx (33) N-Oxyma (34) DmOx (35)

Scheme 25 Synthesis of $\mathrm{N}$-alkyl-cyanoacetamido oximes

In addition, our group has synthesized a series of $\mathrm{N}$-alkyl-cyanoacetamido oximes and examined their additive efficiency with DIC to replace HOSu in couplings that require less activation of the carboxyl group (Scheme 25). ${ }^{86}$ The construction of amide linkages in certain biochemical molecules, peptides and proteins requires stable and less reactive active esters. However, the highly reactive Oxyma active ester and limited reactivity of HOSu esters are restricted. The presence of the carboxamido group confers the $\mathrm{N}$-alkyl-cyanoacetamido oximes with high water solu- bility and results in $\mathbf{\square}$ changes $0 K$ ? $\boldsymbol{\square}$ less reactive active esters. The performance of $\mathrm{N}$-alkyl-cyanoacetamido oximes was tested during the solution-phase coupling reaction of Z-Phg-OH with $\mathrm{H}-\mathrm{Pro}-\mathrm{NH}_{2}$ to form the dipeptide Z-PhgPro- $\mathrm{NH}_{2}$. Remarkably, all the oximes afforded the dipeptide in good yield and with less epimerization than when using HOSu. Of the oximes tested, AmOx and DmOx achieved promising results in terms of optical purity and coupling efficiency (Table 7).

Table 7 Yield and Racemization During the Formation of Z-Phg-Pro$\mathrm{NH}_{2}$

\begin{tabular}{llcr}
\hline Entry & Coupling reagent & Yield (\%) & DL (\%) \\
\hline 1 & DIC/OxymaPure & 89.9 & 1.0 \\
2 & DIC/HOSu & 70.3 & 32.7 \\
3 & DIC/MorOX & 88.4 & 5.7 \\
4 & DIC/PipOx & 86.8 & 10.7 \\
5 & DIC/AmOx & 81.4 & 3.0 \\
6 & DIC/N-Oxyma & 92.1 & 3.8 \\
7 & DIC/DmOx & 93.4 & 8.3 \\
\hline
\end{tabular}

In 2012, Wang et al. reported glyceroacetonide-Oxyma (36) for peptide synthesis in a water-based solvent mixture. ${ }^{87}$ This was the first report of an Oxyma-based additive for aqueous-mediated oligopeptide synthesis. Wang successfully synthesized di, tri and oligopeptides with common $\mathrm{N}$-protected amino acids such as $\mathrm{Cbz}$, Boc, Fmoc, and Ac. All the reactions worked well and gave good to excellent yields without any measurable epimerization (Scheme 26).

The same group further extended this methodology for esterification. They achieved selective esterification of primary alcohols with carboxylic acids by using EDC $\mathbf{\square} E D C l$ in sch 27? and $\mathrm{NaHCO}_{3}$ in the presence of OxymaPure or glyceroacetonide-Oxyma in $5 \% \mathrm{H}_{2} \mathrm{O} / \mathrm{MeCN}$ as the solvent. ${ }^{88}$ In the presence of secondary alcohols, benzoylated products were obtained selectively at the primary hydroxy group. The authors noted that OxymaPure and glyceroacetonide-Oxyma afforded equal conversions and yields, but that it was very difficult to separate OxymaPure from the

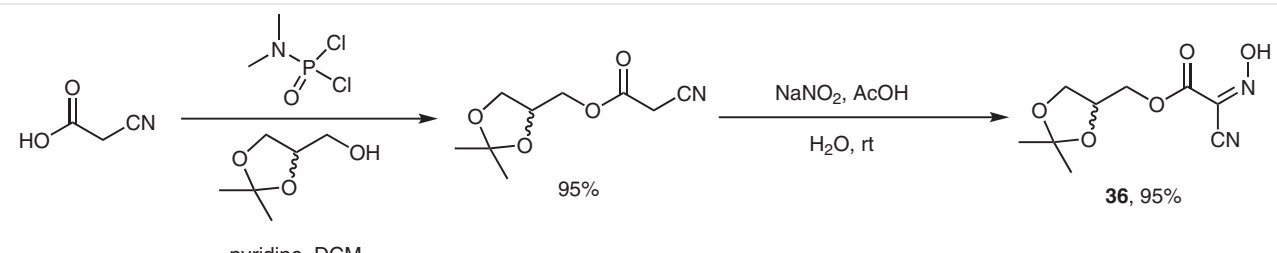

pyridine, DCM

$$
\begin{aligned}
& \mathrm{P}_{1}-\mathrm{A}_{1}-\mathrm{OH}+\mathrm{HCl} \cdot \mathrm{H}-\mathrm{A}_{2}-\mathrm{P}_{2} \quad \mathrm{EDCl}, 36 \quad \mathrm{P}_{1}: \mathrm{Z}, \mathrm{Boc}, \mathrm{Fmoc}, \mathrm{Ac} \\
& \mathrm{P}_{2}: \mathrm{OMe}, \mathrm{NH}_{2}, \mathrm{Ot} \text {-Bu } \\
& A_{1} \text { : mono, dipeptide } \\
& A_{2} \text { : mono, oligopeptide }
\end{aligned}
$$

Scheme 26 The preparation of glyceroacetonide-Oxyma (36) and its use in peptide synthesis $\mathbf{\square}$ changes OK? $\mathbf{\square}$ 
product by column chromatography. In the case of glyceroacetonide-Oxyma, it was removed straightforwardly by standard acidic or basic work-up (Scheme 27).

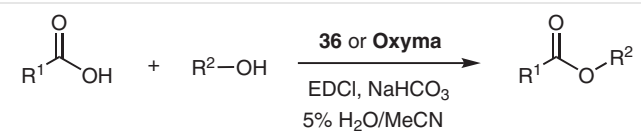<smiles>C[C@H](O)CCOC(=O)c1ccccc1</smiles>

$90 \%$

Scheme 27 Selective esterification of primary alcohols

In 2010, our group reported the synthesis and characterization of 1,3,5-triazinyloxyimino derivatives. ${ }^{89}$ These compounds failed to activate the carboxyl group during the formation of peptide bonds but gave the corresponding $\mathrm{N}$ triazinyl amino acid derivatives as the major products (Scheme 28).

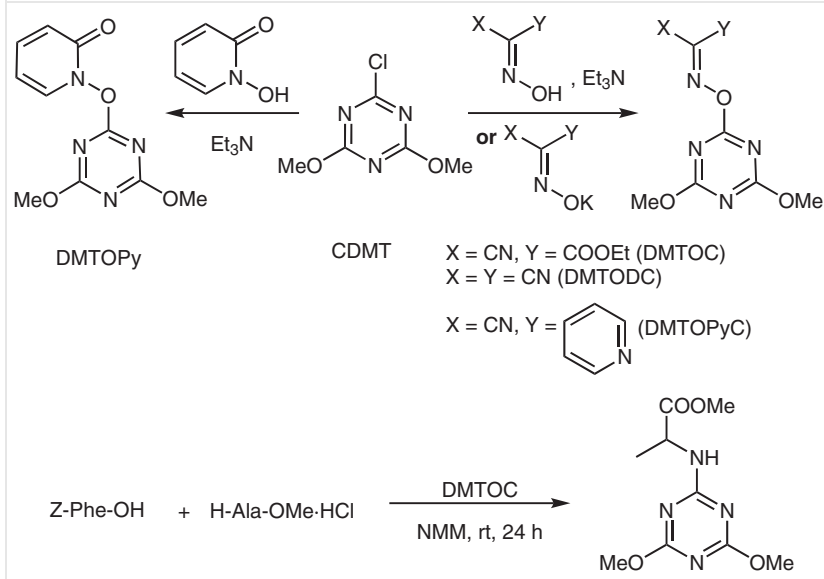

Scheme 28 Synthesis of 1,3,5-triazinyloxyimino derivatives

Later, in 2015, we described that the coupling cocktail of DIC/OxymaPure assisted the synthesis of $\alpha$-ketoamino acid ester 2-[2-(2-acetamidophenyl)-2-oxoacetamido] and 2-\{4[2-(2-acetamidophenyl)-2-oxoacetamido]benzamido\} derivatives ${ }^{90}$ These compounds showed good inhibitory properties and MAO-A $\boldsymbol{\|}$ define? $\mathbf{\square}$ selectivity (Scheme 29).

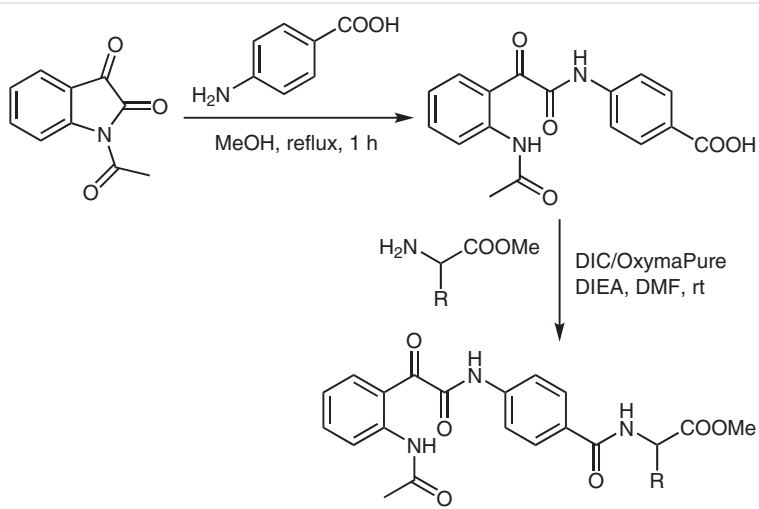

Scheme 29 Synthesis of $\alpha$-ketoamino acid ester 2-[4-[2-(2-acetamidophenyl)-2-oxoacetamido]benzamido] derivatives

In 2018, Wang et al. reported that Oxyma-assisted click chemistry allowed rapid modification of chitin. ${ }^{11}$ The surface modification was achieved without the production of any toxic byproducts or waste organic solvents. This approach emerged as a novel method for the greener production of chitin-based biomaterials.

Very recently, our group disclosed the synthesis of a new series of thiazolidine-2,4-dione carboxamides and amino acid derivatives using DIC/OxymaPure. ${ }^{92}$ The presence of OxymaPure as an additive during the coupling facilitated this reaction, which is not straightforward due to the poor reactivity of the carboxylic moiety, and affords the target products in very good to excellent yields (Scheme 30).
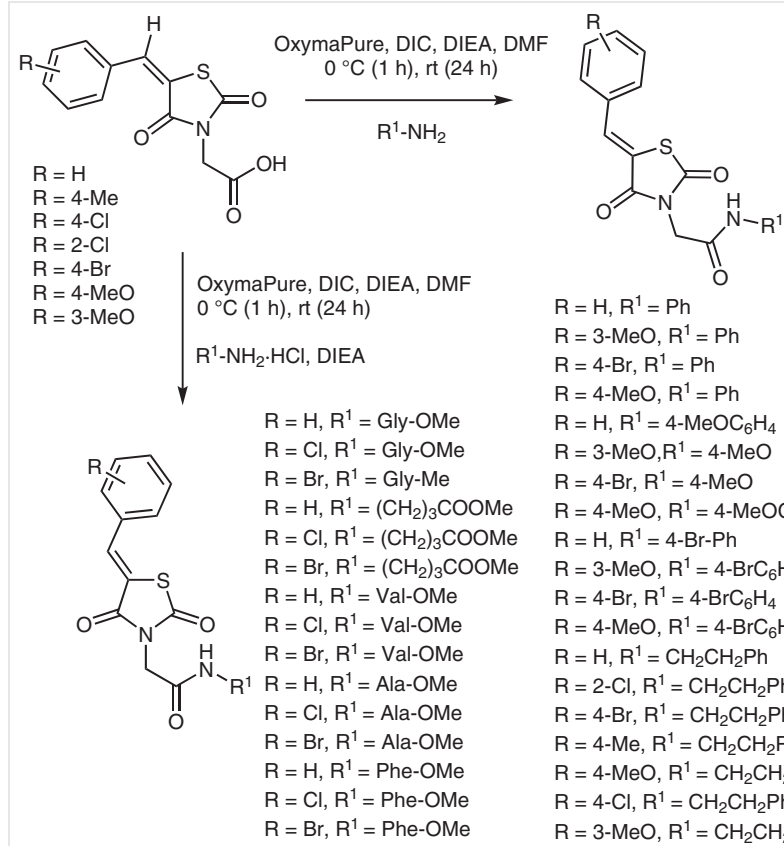

$\mathrm{R}=\mathrm{H}, \mathrm{R}^{1}=\mathrm{Ph}$

$\mathrm{R}=3-\mathrm{MeO}, \mathrm{R}^{1}=\mathrm{Ph}$

$\mathrm{R}=4-\mathrm{Br}, \mathrm{R}^{1}=\mathrm{Ph}$

$\mathrm{R}=4-\mathrm{MeO}, \mathrm{R}^{1}=\mathrm{Ph}$

$\mathrm{R}=\mathrm{H}, \mathrm{R}^{1}=4-\mathrm{MeOC}_{6} \mathrm{H}_{4}$

$\mathrm{R}=3-\mathrm{MeO}, \mathrm{R}^{1}=4-\mathrm{MeO}$

$\mathrm{R}=4-\mathrm{Br}, \mathrm{R}^{1}=4-\mathrm{MeO}$

$\mathrm{R}=4-\mathrm{MeO}, \mathrm{R}^{1}=4-\mathrm{MeOC}_{6} \mathrm{H}_{4}$

$\mathrm{R}=\mathrm{H}, \mathrm{R}^{1}=4-\mathrm{Br}-\mathrm{Ph}$

$\mathrm{R}=3-\mathrm{MeO}, \mathrm{R}^{1}=4-\mathrm{BrC}_{6} \mathrm{H}_{4}$

$\mathrm{R}=4-\mathrm{Br}, \mathrm{R}^{1}=4-\mathrm{BrC}_{6} \mathrm{H}_{4}$

$\mathrm{R}=4-\mathrm{MeO}, \mathrm{R}^{1}=4-\mathrm{BrC}_{6} \mathrm{H}_{4}$

$\mathrm{R}=\mathrm{H}, \mathrm{R}^{1}=\mathrm{CH}_{2} \mathrm{CH}_{2} \mathrm{Ph}$

$\mathrm{R}=2-\mathrm{Cl}, \mathrm{R}^{1}=\mathrm{CH}_{2} \mathrm{CH}_{2} \mathrm{Ph}$

$\mathrm{R}=4-\mathrm{Br}, \mathrm{R}^{1}=\mathrm{CH}_{2} \mathrm{CH}_{2} \mathrm{Ph}$

$\mathrm{R}=4-\mathrm{Me}, \mathrm{R}^{1}=\mathrm{CH}_{2} \mathrm{CH}_{2} \mathrm{Ph}$

$\mathrm{R}=4-\mathrm{MeO}, \mathrm{R}^{1}=\mathrm{CH}_{2} \mathrm{CH}_{2} \mathrm{Ph}$

$\mathrm{R}=4-\mathrm{Cl}, \mathrm{R}^{1}=\mathrm{CH}_{2} \mathrm{CH}_{2} \mathrm{Ph}$

$\mathrm{R}=3-\mathrm{MeO}, \mathrm{R}^{1}=\mathrm{CH}_{2} \mathrm{CH}_{2} \mathrm{Ph}$

Scheme 30 Synthesis of thiazolidine-2,4-dione carboxamides and amino acid derivatives using OxymaPure/DIC $\square$ bottom left, $3^{\text {rd }}$ entry: $R^{1}=$ Gly-Me OK, or Gly-OMe? Also, position of R not specified, as it is in top right list - $\square$ check $E / Z$ conversion between starting material and prod- 
<smiles>On1nnc2ccccc21</smiles>

HOBt<smiles>CCN1C(=O)C(=NO)C(=O)N(CC)C1=S</smiles>

Oxyma-T (44)<smiles>CCOC(=O)/C(C#N)=N/O</smiles>

OxymaPure<smiles>On1nnc2cccnc21</smiles>

HOAt<smiles>CN1C(=O)C(=NO)C(=O)N(C)C1=O</smiles>

Oxyma-B

Scheme 31 Racemization order during the segment coupling of Z-Phe-Val-OH with H-Pro- $\mathrm{NH}_{2}$

\section{Other Oxime-Based Additives and Cou- pling Reagents}

As shown in this review, the structure of OxymaPure is a remarkable scaffold for the preparation of derivatives that seek to modulate the properties of the additive. In this regard, significant research efforts have been channeled into the development of more efficient oxime-based coupling additives and reagents.

In 2010, our group developed highly reactive uronium salts based on isonitroso Meldrum's acid (HONM) (37) for amidation reactions (Figure 6). ${ }^{93}$ The structure of HONM is similar to that of OxymaPure, except that it has two ester groups adjacent to the $N$-hydroxylamine moiety in a sixmembered cyclic structure. The two electron-withdrawing substituents and the geometry enhance the reactivity of HONM compared to OxymaPure. As discussed later, the high reactivity of HONM leads to the formation of an adduct with DIC, and it is restricted to use as an additive with carbodiimide reagents. However, the uronium salts derived from HONM showed higher coupling efficiency than other classical coupling reagents. In this regard, the reactions worked very well and in a very short time, even with less reactive nucleophilic amines such as $p$-chloroaniline.<smiles>CC1(C)OC(=O)C(=NO)C(=O)O1</smiles><smiles>CN(C)C(ON=C1C(=O)OC(C)(C)OC1=O)N(C)C</smiles>

HTMU (38)<smiles>CN(C)C(ON=C1C(=O)OC(C)(C)OC1=O)N1CCOCC1</smiles>

HMMU (39)

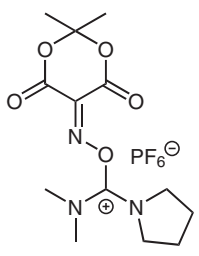

HDmPyMu (40)
Figure 6 Structures of reagents based on Meldrum's acid

Later, in 2014, we introduced a new oxime-based additive, Oxyma-B (41) (Figure 7), which has a similar structure to HONM (based on the structure of barbituric acid) and does not contain any ester moiety. ${ }^{94}$ Oxyma-B showed lower reactivity than HONM, thus allowing acylation with carbodiimide coupling reagents. In addition, it had good solubility in DMF, MeCN, and THF and demonstrated excellent coupling efficiency in both solution- and solid-phase peptide synthesis. Also, Oxyma-B showed greater control of epimerization than OxymaPure and HOAt during the step- wise and segment synthesis of Z-Phe-Val-Pro- $\mathrm{NH}_{2}$, Z-PhgPro- $\mathrm{NH}_{2}$, H-Gly-Ser-Phe- $\mathrm{NH}_{2}$, H-Gly-Cys-Phe- $\mathrm{NH}_{2}$, H-GlyHis-Phe- $\mathrm{NH}_{2}$ and $\mathrm{H}-\mathrm{Gly}-\mathrm{Cys}(\mathrm{Acm})-\mathrm{Phe}-\mathrm{NH}_{2}$ peptides.<smiles>CN1C(=O)C(=NO)C(=O)N(C)C1=O</smiles>

Oxyma-B (41)<smiles>CN1C(=O)C(=NOC(N(C)C)N(C)C)C(=O)N(C)C1=O</smiles>

TOMBU (42)<smiles>CN1C(=O)C(=NOC(C(=O)N2CCOCC2)N(C)C)C(=O)N(C)C1=O</smiles>

COMBU (43)
Figure 7 Structures of Oxyma-B-based reagents

Furthermore, our group developed the Oxyma-B-based novel uronium-type coupling reagents TOMBU (42) and COMBU (43) (Figure 7) for use in peptide bond formation. ${ }^{95}$ These reagents showed higher hydrolytic stability in the solvent DMF than COMU. Also, TOMBU and COMBU outperformed HBTU with respect to coupling yields and optical purity but showed slightly poorer performance than COMU.

In 2016, we reported the novel oxime additive Oxyma-T (44), which belongs to a similar family to HONM and Oxyma-B, but is based on the structure of thiobarbituric acid. ${ }^{96}$ Oxyma-T showed greater capacity to prevent epimerization than HOBt, HOAt, OxymaPure, and Oxyma-B in the stepwise assembly of the dipeptide Z-Phg-Pro- $\mathrm{NH}_{2}$ in solution phase. However, during the segment coupling of Z-Phe-Val$\mathrm{OH}$ with $\mathrm{H}-\mathrm{Pro}-\mathrm{NH}_{2}$, it showed less epimerization than<smiles>CCOP(=O)([O-])OCC</smiles>
DEPO-B (45)

Scheme 32 Synthesis of DEPO-B (45)

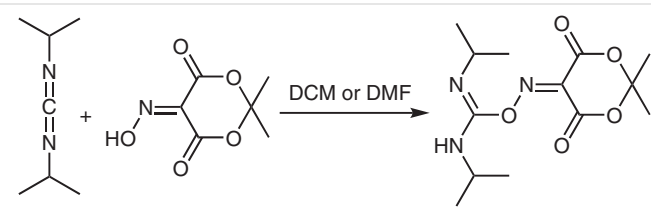

DIC

HONM

adduct 46 
HOBt, but slightly higher epimerization than OxymaPure, HOAt and Oxyma B (Scheme 31). Furthermore, Oxyma-T also afforded a higher yield than HOBt in the solid-phase synthesis of Aib-enkephalin pentapeptide (H-Tyr-Aib-AibPhe-Leu- $\mathrm{NH}_{2}, 43 \%$ and $18 \%$, respectively), but a very poor yield compared to HOAt and OxymaPure (55\% and 71\%, respectively).

Recently, our group described diethylphosphoryl-Oxyma-B घuchange OK? $\mathbf{\square}$ (DEPO-B) (45) as a new Oxyma-Bbased coupling reagent for peptide bond formation. ${ }^{97}$ DEPO-B was easily synthesized by the reaction of Oxyma-B and diethyl chlorophosphate in the presence of a base in DCM (Scheme 32), and was used directly in subsequent reactions without any purification. In the presence of DIEA, the reaction afforded a good yield (74\%), but gave a very poor yield (31\%) with $\mathrm{Et}_{3} \mathrm{~N}$. DEPO-B showed high solubility and good hydrolytic stability in DMF. Indeed, even after 13 days, $85 \%$ of the reagent was observed in this solvent. Hence, DEPO-B has emerged as a suitable reagent for the preparation of stock solutions and for use in an automatic peptide synthesizer.

\section{Side Reactions Using OxymaPure Deriva- tives}

No reaction of termination through a transamidationvia the reaction of an emaino $\mathbf{\square} \mathbf{\square} \mathbf{\square}$ with an ethyl esterhas been described for OxymaPure derivatives, even when using microwave-assisted heating. ${ }^{34,98}$ However, these derivatives can react with DIC. This effect is more pronounced when the oxime is more reactive, which is the case for the oxime derived from Meldrum's acid. ${ }^{93}$ HONM can react directly with DIC and form the corresponding adduct 46 (Scheme 33). In this case, the reaction is significant and leads to the inactivation of DIC and therefore very poor coupling yields. The corresponding uronium salts of this oxime derivative give much better results.

A similar but less severe reaction has been described by Kolis and co-workers at Eli Lilly ${ }^{99}$ when using OxymaPure in combination with DIC. In this case, the formation of hydrogen cyanide ( $\mathrm{HCN}$ ) was observed. The authors noted that the formation of $\mathrm{HCN}$ was exacerbated when excess amounts of DIC and OxymaPure are used relative to the amino acid. However, this side reaction $\mathbf{a}$ changes OK? $\mathbf{\square}$ has also been observed with substoichiometric amounts of DIC and OxymaPure with respect to the protected amino acid (0.5:0.5:1) (Scheme 34).

Very recently, Pawlas, Rasmussen and co-workers ${ }^{100}$ showed that the addition of dimethyl trisulfide (DMTS) during the coupling greatly minimizes the side reaction without penalizing the coupling reaction. DMTS scavenges HCN only and does not react with other components such as DIC and OxymaPure (Scheme 35).

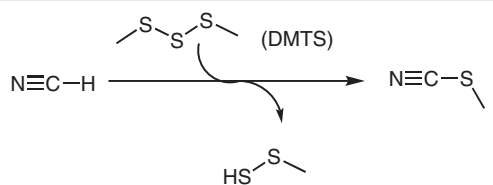

Scheme 35 HCN scavenging by DMTS

\section{Conclusion}

This review summarizes the recent developments and applications of OxymaPure and Oxyma-based reagents in peptide chemistry, including relevant reaction mechanisms. Oxyma-based reagents such as aminium/uronium salts, phosphonium salts, phosphates, sulfonate esters, benzoate esters and carbonates of OxymaPure have shown excellent coupling efficiency in amide bond formation, as well as in biologically active peptides and molecules. Furthermore, several modifications have been made to the structure of OxymaPure and a wide variety of oxime-based additives and reagents have been developed. In all cases, the OxymaPure derivatives have outperformed their HOBt counterparts. In summary, it can be concluded that OxymaPure reagents have broad applicability beyond solid-phase peptide synthesis.

\section{List of Abbreviations}

Alloc: allyloxycarbonyl

BBTZ: benzoyloxybenzotriazole

Boc: $t$-Butyloxycarbonyl

Boc-Oxyma: 2-(tert-butoxycarbonyloxyimino)-2-cyanoacetate
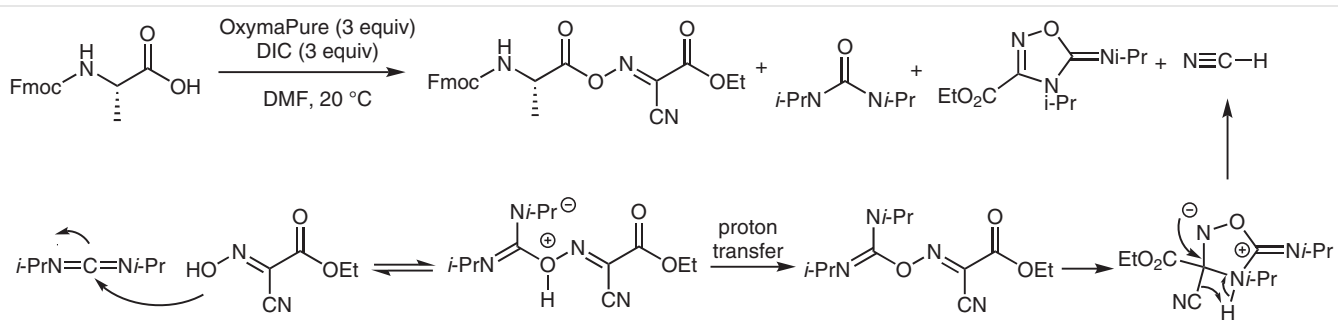

Scheme 34 Reaction of OxymaPure with DIC 
BOP: benzotriazol-1-yloxytris(dimethylamino)phosphoniumhexafluorophosphate

BOP-Cl: N,N'-bis(2-oxo-3-oxazolidinyl)phosphinic chloride $\mathrm{Cbz}, \mathrm{Z}$ : benzyloxycarbonyl

CDMT: 2-chloro-4,6-dimethoxy-1,3,5-triazine

6-Cl-HOBt: 6-chloro-1-hydroxybenzotriazole

COMU: 1-[1-(cyano-2-ethoxy-2-oxoethylideneaminooxy)dimethylamino-morpholinomethylene]methanaminium hexafluorophosphate

CTC: 2-chlorotritylchloride

DBU: 1,8-diazabicyclo[5.4.0]undec-7-ene

DCC: $N, N$-dicyclohexylcarbodiimide

DCM: dichloromethane

DCMT: 2,4-dichloro-6-methoxy-1,3,5-triazine

DEET: $N, N^{\prime}$-diethyl-3-methylbenzamide

DIC: $N, N^{\prime}$-diisopropylcarbodiimide

DIEA: diisopropylethylamine

DMAP: $N, N$-dimethylaminopyridine

DMTS: dimethyl trisulfide

DPGOx: diethylphosphoryl-glyceroacetonide-Oxyma

DPOx: diethylphosphoryl-Oxyma

DPPA: diphenyl phosphoryl azide

Fmoc: 9-fluorenylmethyloxcarbonyl

GVL: $\gamma$-valerolactone

HATTU: S-(7-azabenzotriazol-1-yl)-1,1,3,3-tetramethyluronium hexafluorophosphate $\mathbf{a}$ check abbreviation, should 'S' be 'O'? $\mathbf{m}$

HATU: $\quad N$-[(dimethylamino)-1H-1,2,3-triazolo[4,5- $b]$ pyridin-1-ylmethylene]- $N$-methylmethanaminium hexafluorophosphate $\mathrm{N}$-oxide

HBMTU: 0-(benzotriazol-1-yl)-1,3-dimethyl-1,3-trimethyleneuronium hexafluorophosphate

HBTU: $N$-[(1H-benzotriazol-1-yl)-(dimethylamino)methylene]- $N$-methylmethanaminium hexafluorophosphate $N$ oxide

HCTU: $\quad \mathrm{N}-[(1 \mathrm{H}-6$-chlorobenzotriazol-1-yl)-(dimethylamino)methylene]- $N$-methylmethanaminium hexafluorophosphate $N$-oxide

HDMA: 1-[(dimethylamino)(morpholino)methylene]-1H$[1,2,3]$ triazolo[4,5-b]pyridinium hexafluorophosphate-3oxide

HDMB: 1-[(dimethylamino)(morpholino)methylene]-1Hbenzotriazolium hexafluorophosphate-3-oxide

HOAt: 1-hydroxy-7-azabenzotriazole

HOBI: $N$-hydroxy-2-phenylbenzimidazole

HOBt: 1-hydroxybenzotriazole

HODhbt: 3,4-dihydro-3-hydroxy-4-oxo-1,2,3-benzotriazine

HOI: $N$-hydroxyindolin-2-one

HONM: isonitroso Meldrum's acid

HOPy: 1-hydroxy-2-pyridinone

HOSu: $N$-hydroxysuccinimide

HOTU: $\quad$-[cyano(ethoxycarbonyl)methyleneamino]-
$N, N, N^{\prime}, N^{\prime}$-tetramethyluronium hexafluorophosphate MTBD: 7-methyl-1,5,7-triazabicyclo[4.4.0]dec-5-ene 4-NBsOXY ( $p$-NBsOXY): 2-cyano-2-(4-nitrophenylsulfonyloxyimino)acetate

NFM: $N$-formylmorpholine

NMM: $N$-methylmorpholine

o-NosylOXY: ethyl 2-cyano-2-(2-nitrobenzenesulfonyloxyimino)acetate

OxymaPure: ethyl 2-cyano-2-(hydroxyimino)acetate

PyAOP: [(7-azabenzotriazol-1-yl)oxy]tris(pyrrolidino)phosphonium hexafluorophosphate

PyBOP: benzotriazol-1-yloxytri(pyrrolidino)phosphonium hexafluorophosphate

PyBroP: bromotri(pyrrolidino)phosphonium hexafluorophosphate

PyCloP: chlorotri(pyrrolidino)phosphonium hexafluorophosphate

PyClock घuchange OK?םш: (6-chloro-benzotriazol-1yloxy)tris(pyrrolidino)phosphonium hexafluorophosphate PyOxB: $\quad 0$-[(cyano(ethoxycarbonyl)methyliden)amino]yloxytripyrrolidinophosphonium tetrafluoroborate

PyOxim (PyOxP): 0 -[(cyano(ethoxycarbonyl)methyliden)amino]yloxytripyrrolidinophosphonium hexafluorophosphate

SAHA: suberoylanilide hydroxamic acid

SPPS: solid-phase peptide synthesis

TATU: $\quad N-[($ dimethylamino)-1H-1,2,3-triazolo[4,5-b]pyridin-1-ylmethylene]- $N$-methylmethanaminium tetrafluoroborate $\mathrm{N}$-oxide

TBTU: $\quad N$-[(1H-benzotriazol-1-yl)(dimethylamino)methylene]- $N$-methylmethanaminium tetrafluoroborate $N$-oxide TCBOXY: (E)-ethyl-2-cyano-2-\{[(2,4,6-trichlorobenzoyl)oxy]imino\}acetate

TFFH: tetramethylfluoroformamidiniumhexafluorophosphate

TOTU: $\quad 0$-[cyano(ethoxycarbonyl)methyleneamino]$N, N, N^{\prime}, N^{\prime}$-tetramethyluronium tetrafluoroborate

Trt: trityl

T3P: propane phosphonic acid anhydride

\section{Funding Information}

We are grateful to the American Chemical Society (ACS) Green Chemistry Institute (GCI) (Pharmaceutical Roundtable Ignition Grant) for funding S.R.M. In addition, the work in laboratory of the authors was funded in part by the following: the South African Agency for Science and Technology Advancement, The National Research Foundation (NRF) (Blue Sky's Research Programme, Grant No. 120386) and the University of KwaZulu-Natal (South Africa); the Ministerio de Ciencia e Innovación (Spanish Ministry of Science, Innovation) (RTI2018093831-B-100), the Departament d'Innovació, Universitats i Empresa, Generalitat de Catalunya (2017 SGR 1439) and the Ministerio de Economía y Competitividad; and the International Scientific Partnership Program ISPP at King Saud University (ISPP\# 0061). — changes $\mathrm{OK} ? \mathbf{\square}$ 


\section{Acknowledgment}

Special thanks go to Mr. Yoav Luxembourg for encouraging our work on coupling reagents.

\section{References}

(1) Scarso, A.; Pellizzaro, L.; De Lucchi, O.; Linden, A.; Fabris, F. Angew. Chem. Int. Ed. 2007, 46, 4972.

(2) Collins, J.; Xiao, Z.; Müllner, M.; Connal, L. A. Polym. Chem. 2016, 7, 3812.

(3) Bednarczyk-Cwynar, B.; Zaprutko, L. Phytochem. Rev. 2015, 14, 203.

(4) Bergström, M. A.; Andersson, S. I.; Broo, K.; Luthman, K.; Karlberg, A.-T. J. Med. Chem. 2008, 51, 2541.

(5) Li, J.; Hu, Y.; Zhang, D.; Liu, Q.; Dong, Y.; Liu, H. Adv. Synth. Catal. 2017, 359, 710.

(6) Nikitjuka, A.; Jirgensons, A. Chem. Heterocycl. Compd. 2014, 49, 1544.

(7) Sahyoun, T.; Arrault, A.; Schneider, R. Molecules 2019, 24, 2470; a $\mathbf{a d d e d}$ page no.-OK? $\mathbf{\square}$.

(8) Bednarczyk-Cwynar, B. Nat. Prod. Commun. 2011, 6, 1813.

(9) Zhou, X.-T.; Yuan, Q.-L.; Ji, H.-B. Tetrahedron Lett. 2010, 51, 613.

(10) Ramón, R. S.; Bosson, J.; Díez-González, S.; Marion, N.; Nolan, S. P. J. Org. Chem. 2010, 75, 1197.

(11) Lemercier, B. C.; Pierce, J. G. J. Org. Chem. 2014, 79, 2321.

(12) Ding, R.; Liu, Y.; Han, M.; Jiao, W.; Li, J.; Tian, H.; Sun, B. J. Org. Chem. 2018, 83, 12939.

(13) Li, Y.-T.; Liao, B.-S.; Chen, H.-P.; Liu, S.-T. Synthesis 2011, 2639.

(14) Santosh Kumar, S. C.; Vijendra Kumar, N.; Srinivas, P.; Bettadaiah, B. K. Synthesis 2014, 46, 1847.

(15) Kumar, R.; Chowdhury, B. Ind. Eng. Chem. Res. 2014, 53, 16587.

(16) Bruton, E. A.; Brammer, L.; Pigge, F. C.; Aakeröy, C. B.; Leinen, D. S. New J. Chem. 2003, 27, 1084.

(17) Aakeröy, C. B.; Sinha, A. S.; Epa, K. N.; Chopade, P. D.; Smith, M. M.; Desper, J. Cryst. Growth Des. 2013, 13, 2687.

(18) Subirós-Funosas, R.; Prohens, R.; Barbas, R.; El-Faham, A.; Albericio, F. Chem. Eur. J. 2009, 15, 9394.

(19) Subiros-Funosas, R.; Khattab, S. N.; Nieto-Rodriguez, L.; ElFaham, A.; Albericio, F. Aldrichimica Acta 2013, 46, 21; moriginal ref now cited, rather than ChemInform abstract; check $\mathbf{\square}$.

(20) Isidro-Llobet, A.; Kenworthy, M. N.; Mukherjee, S.; Kopach, M. E.; Wegner, K.; Gallou, F.; Smith, A. G.; Roschangar, F. J. Org. Chem. 2019, 84, 4615.

(21) Reszka, P.; Methling, K.; Lalk, M.; Xiao, Z.; Weisz, K.; Bednarski, P. J. Tetrahedron: Asymmetry 2008, 19, 49.

(22) Abdelmoty, I.; Albericio, F.; Carpino, L. A.; Foxman, B. M.; Kates, S. A. Lett. Pept. Sci. 1994, 1, 57.

(23) Marder, O.; Shvo, Y.; Albericio, F. Chim. Oggi 2002, 20, 37; - $\mathbf{m u p d a t e d}$ ref OK? $\boldsymbol{\square}$.

(24) Hood, C. A.; Fuentes, G.; Patel, H.; Page, K.; Menakuru, M.; Park, J. H. J. Pept. Sci. 2008, 14, 97.

(25) Speicher, A.; Klaus, T.; Eicher, T. J. Prakt. Chem./Chem. Ztg. 1998, $340,581$.

(26) Sureshbabu, V. V.; Lalithamba, H. S.; Narendra, N.; Hemantha, H. P. Org. Biomol. Chem. 2010, 8, 835.

(27) McKnelly, K. J.; Sokol, W.; Nowick, J. S. J. Org. Chem. 2020, 85, 1764.

(28) Wehrstedt, K. D.; Wandrey, P. A.; Heitkamp, D. J. Hazard. Mater. 2005, 126, 1.

(29) El-Faham, A.; Subirós Funosas, R.; Prohens, R.; Albericio, F.

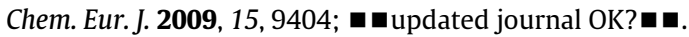

(30) El-Faham, A.; Albericio, F. J. Pept. Sci. 2010, 16, 6.

(31) Hjelmgaard, T.; Faure, S.; Staerk, D.; Taillefumier, C.; Nielsen, J. Org. Biomol. Chem. 2011, 9, 6832.

(32) Hjørringgaard, C. U.; Brust, A.; Alewood, P. F. J. Pept. Sci. 2012, $18,199$.

(33) Samarasimhareddy, M.; Hosahalli, P. H.; Kuppanna, A.; Vommina, V. S. Protein Pept. Lett. 2012, 19, 406.

(34) Subiros-Funosas, R.; Acosta, G. A.; El-Faham, A.; Albericio, F. Tetrahedron Lett. 2009, 50, 6200.

(35) Tyrrell, E.; Brawn, P.; Carew, M.; Greenwood, I. Tetrahedron Lett. 2011, 52, 369.

(36) El-Faham, A.; Funosas, R. S.; Prohens, R.; Albericio, F. Chem. Eur. J. 2009, 15, 9404.

(37) Subirós-Funosas, R.; Nieto-Rodriguez, L.; Jensen, K. J.; Albericio, F. J. Pept. Sci. 2013, 19, 408.

(38) Kumar, A.; Jad, Y. E.; de la Torre, B. G.; El-Faham, A.; Albericio, F. J. Pept. Sci. 2017, 23, 763.

(39) Gabriel C. M., Keener M., Gallou F., Lipshutz B. H.; Org. Lett.; 2015, 17: 3968.

(40) Cortes-Clerget, M.; Berthon, J.-Y.; Krolikiewicz-Renimel, I.; Chaisemartin, L.; Lipshutz, B. H. Green Chem. 2017, 19, 4263.

(41) Twibanire, J.-d'. A. K.; Grindley, T. B. Org. Lett. 2011, 13, 2988.

(42) Panguluri, N. R.; Basavaprabhu; Sureshbabu, V. V. Int. J. Pept. Res. Ther. 2014, 20, 377.

(43) Junker, A.; Schepmann, D.; Yamaguchi, J.; Itami, K.; Faust, A.; Kopka, K.; Wagner, S.; Wünsch, B. Org. Biomol. Chem. 2014, 12, 177.

(44) Miao, Y.; Djedaïni-Pilard, F.; Bonnet, V. Beilstein J. Org. Chem. 2014, 10, 2654.

(45) Manabe, S.; Ito, Y. Beilstein J. Org. Chem. 2016, 12, 328.

(46) Withey, J. M.; Bajic, A. J. Chem. Educ. 2015, 92, 175.

(47) Scholz, M. S.; Wingen, L. M. Inorg. Chem. 2017, 56, 5510.

(48) Poock, C.; Kalesse, M. Org. Lett. 2017, 19, 4536.

(49) Albericio, F.; Bofill, J. M.; El-Faham, A.; Kates, S. A. J. Org. Chem. 1998, 63, 9678.

(50) Story, S. C.; Aldrich, J. V. Int. J. Pept. Protein Res. 1994, 43, 292.

(51) Albericio, F.; Cases, M.; Alsina, J.; Triolo, S. A.; Carpino, L. A.; Kates, S. A. Tetrahedron Lett. 1997, 38, 4853.

(52) Subirós-Funosas, R.; El-Faham, A.; Albericio, F. Org. Biomol. Chem. 2010, 8, 3665.

(53) Dettin, M.; Silvestri, D.; Danesin, R.; Cretaio, E.; Picariello, G.; Casarin, E.; Sonato, A.; Romanato, F.; Morpurgo, M. Molecules 2012, 17, 11026.

(54) El-Faham, A.; Khattab, S. N.; Subirós-Funosas, R.; Albericio, F. J. Pept. Sci. 2014, 20, 1.

(55) Mitachi, K.; Kurosu, Y. E.; Hazlett, B. T.; Kurosu, M. J. Pept. Sci. 2016, 22, 186.

(56) Khattab, S. N. Chem. Pharm. Bull. 2010, 58, 501.

(57) Palakurthy, N. B.; Dev, D.; Rana, S.; Nadimpally, K. C.; Mandal, B. Eur. J. Org. Chem. 2013, 2627.

(58) Dev, D.; Palakurthy, N. B.; Kumar, N.; Mandal, B. Tetrahedron Lett. 2013, 54, 4397.

(59) Dev, D.; Palakurthy, N. B.; Thalluri, K.; Chandra, J.; Mandal, B. J. Org. Chem. 2014, 79, 5420.

(60) Manne, S. R.; Chandra, J.; Giri, R. S.; Kalita, T.; Mandal, B. ChemistrySelect 2018, 3, 992.

(61) Dev, D.; Chandra, J.; Palakurthy, N. B.; Thalluri, K.; Kalita, T.; Mandal, B. Asian J. Org. Chem. 2016, 5, 663.

(62) Crescenzi, O.; Tomaselli, S.; Guerrini, R.; Salvadori, S.; D'Ursi, A. M.; Temussi, P. A.; Picone, D. Eur. J. Biochem. 2002, 269, 5642.

(63) Thalluri, K.; Manne, S. R.; Dev, D.; Mandal, B. J. Org. Chem. 2014, $79,3765$. 
(64) Chandra, J.; Manne, S. R.; Mondal, S.; Mandal, B. ACS Omega 2018, 3, 6120.

(65) Burugupalli, S.; Shah, S.; van der Peet, P. L.; Arora, S.; White, J. M.; Williams, S. J. Org. Biomol. Chem. 2016, 14, 97.

(66) Thalluri, K.; Nadimpally, K. C.; Chakravarty, M. P.; Paul, A.; Mandal, B. Adv. Synth. Catal. 2013, 355, 448.

(67) Manne, S. R.; Thalluri, K.; Giri, R. S.; Paul, A.; Mandal, B. Tetrahedron Lett. 2015, 56, 6108.

(68) Marks, P. A. Oncogene 2007, 26, 1351.

(69) Grant, S.; Easley, C.; Kirkpatrick, P. Nat. Rev. Drug Discovery 2007, 6, 21.

(70) Salmi-Smail, C.; Fabre, A.; Dequiedt, F.; Restouin, A.; Castellano, R.; Garbit, S.; Roche, P.; Morelli, X.; Brunel, J. M.; Collette, Y. J. Med. Chem. 2010, 53, 3038.

(71) Manne, S. R.; Thalluri, K.; Giri, R. S.; Chandra, J.; Mandal, B. Adv. Synth. Catal. 2017, 359, 168.

(72) Khattab, S. N.; Subirós-Funosas, R.; El-Faham, A.; Albericio, F. Eur. J. Org. Chem. 2010, 3275.

(73) Carpino, L. A. Acc. Chem. Res. 1987, 20, 401.

(74) Carpino, L. A.; Han, G. Y. J. Org. Chem. 1972, 37, 3404.

(75) Lozanov, V.; Petrov, S.; Mitev, V. J. Chromatogr. A 2004, 1025, 201.

(76) Paquet, A. Can. J. Biochem. 1982, 60, 976.

(77) Tessier, M.; Albericio, F.; Pedroso, E.; Grandas, A.; Eritja, R.; Giralt, E.; Granier, C.; van Rietschoten, J. Int. J. Pept. Protein Res. 1983, 22, 125

(78) Sigler, G. F.; Fuller, W. D.; Chaturvedi, N. C.; Goodman, M.; Verlander, M. Biopolymers 1983, 22, 2157.

(79) Hlebowicz, E.; Andersen, A. J.; Andersson, L.; Moss, B. A. J. Pept. Res. 2005, 65, 90.

(80) Kumar, A.; Sharma, A.; Haimov, E.; El-Faham, A.; de la Torre, B. G.; Albericio, F. Org. Process Res. Dev. 2017, 21, 1533.

(81) Masumi, I. Bull. Chem. Soc. Jpn. 1973, 46, 2219.

(82) Spengler, J.; Fernandez-Llamazares, A.-I.; Albericio, F. ACS Comb. Sci. 2013, 15, 229.

(83) Subirós-Funosas, R.; El-Faham, A.; Albericio, F. Biopolymers 2012, 98, 89.
(84) Cherkupally, P.; Acosta, G. A.; Nieto-Rodriguez, L.; Spengler, J.; Rodriguez, H.; Khattab, S. N.; El-Faham, A.; Shamis, M.; Luxembourg, Y.; Prohens, R.; Subiros-Funosas, R.; Albericio, F. Eur. J. Org. Chem. 2013, 6372.

(85) Eylar, E.; Brostoff, S.; Hashim, G.; Caccam, J.; Burnett, P. J. Biol. Chem. 1971, 246, 5770.

(86) Khattab, S. N.; Subirós-Funosas, R.; El-Faham, A.; Albericio, F. ChemistryOpen 2012, 1, 147.

(87) Wang, Q.; Wang, Y.; Kurosu, M. Org. Lett. 2012, 14, 3372.

(88) Wang, Y.; Aleiwi, B. A.; Wang, Q.; Kurosu, M. Org. Lett. 2012, 14, 4910.

(89) Al-Warhi, T. I.; Al-Hazimi, H.; El-Faham, A.; Albericio, F. Molecules 2010, 15, 9403.

(90) El-Faham, A.; Al Marhoon, Z.; Abdel-Megeed, A.; Khattab, S. N.; Bekhit, A. A.; Albericio, F. Bioorg. Med. Chem. Lett. 2015, 25, 70.

(91) Wang, D.; Li, J.; Salazar-Alvarez, G.; McKee, L. S.; Srivastava, V.; Sellberg, J. A.; Bulone, V.; Hsieh, Y. S. Y. Green Chem. 2018, 20, 2091.

(92) Abd Alhameed, R.; Almarhoon, Z.; Bukhari, S. I.; El-Faham, A.; de la Torre, B. G.; Albericio, F. Molecules 2020, 25, 105.

(93) El-Faham, A.; Subirós-Funosas, R.; Albericio, F. Eur. J. Org. Chem. 2010, 3641.

(94) Jad, Y. E.; Khattab, S. N.; de la Torre, B. G.; Govender, T.; Kruger, H. G.; El-Faham, A.; Albericio, F. Org. Biomol. Chem. 2014, 12, 8379.

(95) Jad, Y. E.; Khattab, S. N.; De la Torre, B. G.; Govender, T.; Kruger, H. G.; El-Faham, A.; Albericio, F. Molecules 2014, 19, 18953.

(96) Jad, Y. E.; de la Torre, B. G.; Govender, T.; Kruger, H. G.; ElFaham, A.; Albericio, F. Tetrahedron Lett. 2016, 57, 3523.

(97) Kumar, A.; Jad, Y. E.; El-Faham, A.; de la Torre, B. G.; Albericio, F. Lett. Org. Chem. 2019, 16, 30.

(98) Ben Haj Salah, K.; Inguimbert, N. Org. Lett. 2014, 16, 1783.

(99) McFarland, A. D.; Buser, J. Y.; Embry, M. C.; Held, C. B.; Kolis, S. P. Org. Process Res. Dev. 2019, 23, 2099.

(100) Erny, M.; Lundqvist, M.; Rasmussen, J. H.; Ludemann-Hombourger, O.; Bihel, F.; Pawlas, J. Org. Process Res. Dev. 2020, 24, 1341; $\mathbf{m a d d e d}$ Vol./page no OK? $\mathbf{\square}$. 